Sharif University of Technology
Scientia Iranica
SCIENTIA $\quad \begin{gathered}\text { Transactions D: Computer Science ES Engineering and Electrical Engineering } \\ \text { http://scientiairanica.sharif.edu }\end{gathered}$

\title{
Control of doubly-fed induction generator with extended state observer under unbalanced grid conditions
}

\author{
A.A. Vali, S.M.H. Hosseini*, and J. Olamaei \\ Department of Electrical Engineering, South Tehran Branch, Islamic Azad University, Mahallati Exp., Tehran, P.O. Box \\ 8199653471 , Iran.
}

Received 29 December 2019; received in revised form 5 September 2020; accepted 18 October 2020

\author{
KEYWORDS \\ Doubly-Fed Induction \\ Generator (DFIG); \\ Rotor Side Converter \\ (RSC); \\ Grid Side Converter \\ (GSC); \\ Extended State \\ Observer (ESO); \\ Unbalanced grid.
}

\begin{abstract}
Under unbalanced grid conditions, in a Doubly-Fed Induction Generator (DFIG), voltage, current, and flux of the stator become asymmetric. Therefore, activereactive power and torque will be oscillating. In DFIG, controlling Rotor Side Converter (RSC) aims to eliminate power and torque oscillations. However, simultaneous elimination of power and torque oscillations is not possible. Also, Grid Side Converter (GSC) aims to regulate DC-link voltage. In this paper, in order to regulate DC-link voltage, an Extended State Observer (ESO) based on a Generalized Proportional-Integral (GPI) controller is employed. In this controlling method, DC-link voltage is controlled without measuring the GSC current and due to use of the GPI controller, the improved dynamic response is resistant against voltage changes and the settling time is reduced. A versatile Rotor Position Computation Algorithm (RPCA) is utilized to measure the rotor speed. This algorithm is simple, accurate, and resistant to changes in the resistance of the rotor and stator. The simulations are implemented by MATLAB software in the synchronous positive and negative sequence references $(d-q)$.
\end{abstract}

(C) 2022 Sharif University of Technology. All rights reserved.

\section{Introduction}

Dynamic modeling and control of Doubly-Fed Induction Generator (DFIG)-based wind generation system operating during unbalanced grid conditions were studied in $[1,2]$. In a DFIG under unbalanced grid conditions, voltage, current, and flux of the stator become asymmetric. If voltage unbalance is not

*. Corresponding author. Tel.: 03132270425

E-mail addresses: aliakbarvali@yahoo.com (A.A. Vali);

Smhh110@azad.ac.ir (S.M.H. Hosseini);

J_olamaei@azad.ac.i (J.Olamaei)

doi: $10.24200 /$ sci. 2020.55054 .4054 taken into account by the control system, the stator current could become highly unbalanced even with a small unbalanced stator voltage [3]. Under unbalanced grid conditions, the negative sequence component of stator voltage leads to the oscillation of power (activereactive) and electromagnetic torque with twice the grid frequency. Power fluctuations lead to increased temperature in the stator winding, and torque fluctuations lead to mechanical tension on the rotor [4]. Control methods of DFIG are conducted based on the Voltage Orientation Control (VOC) or Flux Orientation Control (FOC). In the VOC method, the current signal controls the active power along with the direct axis (Id) and reactive power along with the quadrature axis $(\mathrm{Iq})$. The inverse is true in the 
case of FOC method [5-7]. Controlling of DFIG in order to eliminate power and torque oscillations under unbalanced grid voltage was studied in [8]. In DFIG, Rotor Side Converter (RSC) is controlled with the aim of eliminating power and torque oscillations. However, simultaneous elimination of the stator active/reactive power and torque oscillations is not possible [9]. For the purpose of controlling the power and torque by RSC, multiple controller methods have been used. In [10], a Sliding Mode Controller with Fractional order sliding surface (SMC-F) based on robust control designed for controlling the performance of DFIG's RSC was used. In this control method, to overcome uncertainties and incoming disturbances to the system, a sliding mode controller was used. In order to increase the degree of freedom and robustness of the controller further, the sliding surface is selected as a fractional order form. In addition to increasing the performance of the controller, the use of a robust sliding mode controller facilitates reducing chattering phenomen on in the input control signal. In [11], for controlling the performance of DFIG's RSC nonlinear robust control approach, an Extended State Observer based on the Backstepping controller (ESO-BS) was used. In this controller, the approach has a simple design and low computational complexity, which can eliminate nonlinear factors. As a result, computation complexity is reduced. This paper aims to reduce the steady-state error value to zero and improve the accuracy of controlling the RSC; to this end, a Proportional-Integral (PI) controller is used. Finally, this method control is compared with SMC-F and ESO-BS. In recent years, for calculating the rotor speed of the DFIG, a number of sensor-less methods were proposed $[12,13]$. In $[14,15]$, to calculate the rotor speed of the DFIG, Model Reference Adaptive System (MRAS) was used. The weakness of MRAS observers was that it ran in the stator reference frame. Thus, designing the control parameter can be difficult and results may be incorrect or be unstable. In this paper, to measure the rotor speed of DFIG, a versatile Rotor Position Computation Algorithm (RPCA) is used. In the algorithm, without the need for estimating the stator flux, the rotor position is estimated by means of measured stator as well as rotor voltages and current. This algorithm is simple and effective and does not require direct estimation of the stator flux. One of the most important advantages of this scheme is that the calculations do not use any approximation. This algorithm is robust against variations of stator and rotor resistances and is only dependent on the estimation of the DFIG mutual inductance [16-18].

Under unbalanced grid conditions, a common DClink voltage is controlled by a Grid Side Converter (GSC). In order to control the DC-link voltage, multiple control methods have been used. In [19], to control the DC-link voltage, the FUZZY-PI controller was used. Complexity of performance and analysis is one of the most important disadvantages of this controller. In [20], to control DC-link voltage, a nonlinear observer controller based on sliding mode control was used. This controller enjoys proper performance in controlling the DC-link voltage, but remains slightly complicated in terms of analysis and regulation. To solve this problem, authors in [21] proposed a nonlinear observer controller based on high order sliding mode control. This controller has high sensitivity to a variety of disturbances and uncertainties. In $[22,23]$, to control the DC-link voltage, one cycle controller was used. In this controller, the dynamic response is enhanced and it is resistant to voltage changes; however, it is complex in terms of the optimization of responses. In this paper, for controlling the DC-link voltage, an Expanded Sate Observer (ESO) based on a Generalized Proportional-Integral (GPI) controller is introduced. In this controller, due to use of the GPI controller, the improved dynamic response is resistant against voltage changes and settling time is reduced [24-29]. Finally, this control method is compared with SMC-F, ESO-BS, $\mathrm{PI}$, and Proportional (P) controller.

\section{Materials and methods}

\subsection{Dynamic model of DFIG}

The existing DFIG models are primarily developed on the basis of balanced grid conditions. Under unbalanced grid conditions, both positive and negative sequence components of voltage and current need to be considered in order to accurately describe the system behavior. With the aim of obtaining decoupled control between torque/active power and reactive power, the $\mathrm{d}$-axis in the synchronous reference frame is generally oriented along the stator flux vector or the stator voltage vector.

The equivalent circuit of a DFIG can be expressed in different reference frames such as the stationary frame, the rotor frame, or the synchronous frame fixed to either the stator voltage or the stator flux. A general expression of a DFIG model in an arbitrary (d-q) reference frame rotating at the angular speed of $\omega_{S}$ is shown in Figure 1. The stator and rotor flux are given respectively as follows:

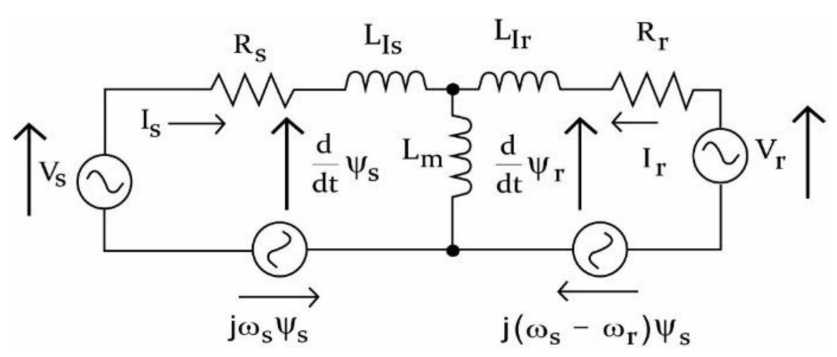

Figure 1. DFIG (Doubly-Fed Induction Generator) model in (d-q) reference frame. 


$$
\Psi_{s}=L_{s} i_{s}+L_{m} i_{r}, \Psi_{r}=L_{r} i_{r}+L_{m} i_{s} .
$$

From Figure 1, the stator and rotor voltages in the arbitrary reference frame can be expressed orderly as follows:

$$
\begin{aligned}
& V_{s}=R_{s} i_{s}+\frac{d}{d t} \psi_{s}+j \omega_{s} \psi_{s} \\
& V_{r}=R_{r} i_{r}+\frac{d}{d t} \psi_{r}+j\left(\omega_{s}-\omega_{r}\right) \psi_{r} .
\end{aligned}
$$

According to Eq. (1), the rotor flux and stator current can be expressed orderly as follows:

$$
\psi_{r}=\frac{L_{m}}{L_{s}} \psi_{s}+\sigma L_{r} i_{r}, \quad i_{s}=\frac{1}{L_{s}}\left(\psi_{s}-L_{m} i_{r}\right) .
$$

Substituting Eq. (4) into Eq. (3) yields the rotor voltage in the arbitrary rotating reference frame as:

$$
\begin{aligned}
V_{r}= & R_{r} i_{r}+\sigma L_{r} \frac{d}{d t} i_{r}+\frac{L_{m}}{L_{s}} \frac{d}{d t} \psi_{s} \\
& +j\left(\omega_{\text {slip }}\right)\left(\sigma L_{r} i_{r}+\frac{L_{m}}{L_{s}} \psi s\right),
\end{aligned}
$$

where $\sigma=1-\frac{L_{m}^{2}}{L_{s} L_{r}}$ is the leakage factor. In Eq. (1)(5) and $V_{s}$ and $V_{r}$ are terminal voltages of stator and rotor, $i_{s}, i_{r}$ output currents of stator and rotor, $\psi_{s}$ and $\psi_{r}$ leakage flux of stator and rotor, $R_{s}$ and $R_{r}$ the resistance of stator and rotor, $L_{s}$ and $L_{r}$ inductance of stator and rotor, and $L_{m}$ is magnetizing inductance, $\omega_{s}, \omega_{r}$ and $\omega_{\text {slip }}$ synchronous speeds of stator, rotor speed, and slip frequency, respectively [1-4].

\subsubsection{Balanced grid conditions}

Many studies have investigated a detailed model of the DFIG system under a balanced network supply. Thus, only a brief description is given here. Figure 2 shows the phasor diagram of the variable $F$, which represents voltage, current, or flux, in the stator flux oriented (dq), stator $(\alpha-\beta)$, and rotor $\left(\alpha_{r}-\beta_{r}\right)$ reference frames. The transformation between (d-q), $\left(\alpha_{-} \beta\right)$, and $\left(\alpha_{r}-\beta_{r}\right)$ reference frames is given by:

$$
F_{d q}=F_{\alpha \beta} e^{-j\left(\omega_{s} t\right)}, \quad F_{\alpha \beta}=F_{\alpha r \beta r} e^{j\left(\omega_{r} t\right)} .
$$

In balanced grid conditions, stator voltage is usually

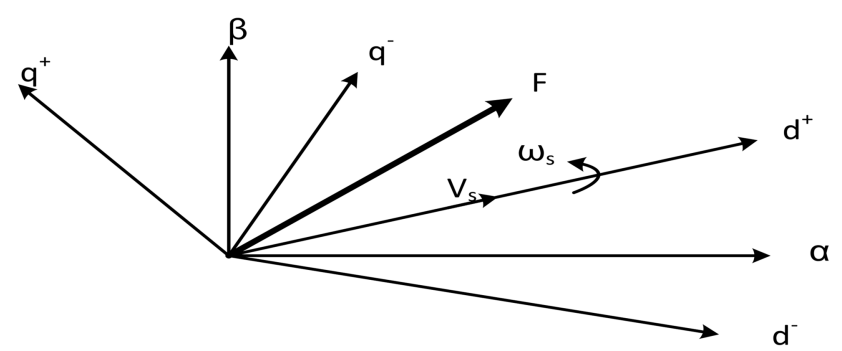

Figure 2. Diagram of reference frame, positive $\left(d q^{+}\right)$and negative $\left(d q^{-}\right)$. constant that leads to stator flux to remain constant. Therefore, relationship with Eq. (5) is expressed below:

$$
V_{r}=R_{r} i_{r}+\sigma L_{r} \frac{d}{d t} i_{r}+j\left(\omega_{s l i p}\right)\left(\sigma L_{r} i_{r}+\frac{L_{m}}{L_{s}} \psi_{s}\right) .
$$

Eq. (7) in (d-q) reference frame components yields:

$$
\begin{gathered}
\frac{d}{d t}\left[\begin{array}{c}
I_{r d} \\
I_{r q}
\end{array}\right]=\left[\begin{array}{cc}
-\frac{R_{r}}{\sigma L_{r}} & \omega_{s l i p} \\
-\omega_{s l i p} & -\frac{R_{r}}{\sigma L_{r}}
\end{array}\right]\left[\begin{array}{c}
I_{r d} \\
I_{r q}
\end{array}\right] \\
+\frac{L_{m} \omega_{s l i p}}{\sigma L_{r} L_{s}}\left[\begin{array}{c}
\psi_{s q} \\
-\psi_{s q}
\end{array}\right]+\frac{1}{\sigma L_{r}}\left[\begin{array}{c}
V_{r d} \\
V_{r q}
\end{array}\right] .
\end{gathered}
$$

The stator's output active power $\left(p_{s}\right)$ and reactive power $\left(q_{s}\right)$ can be calculated as follows:

$$
\begin{aligned}
p_{s}+j q_{s} & =-\frac{3}{2} V_{s d q}^{+} \times I_{s d q}^{+} \approx-\frac{3}{2} j \omega_{s} \psi_{s} \times\left(\hat{\psi}_{s}-L_{m} I_{r}\right) \\
& =-\frac{3}{2} \omega_{s}\left(j \psi_{s}\right) \times \frac{1}{L_{s}}\left[\left(\psi_{s}-L_{m} I_{r d}\right)+j L_{m} I_{r q}\right] \\
& =\frac{3}{2} \frac{\omega_{s}}{L_{s}}\left[\psi_{s} L_{m} I_{r q}-j \psi_{s}\left(\psi_{s}-L_{m} I_{r d}\right)\right] .
\end{aligned}
$$

Thus, the stator active and reactive powers are given by:

$$
p_{s}=\frac{3}{2} \frac{\omega_{s}}{L_{s}} \psi_{s} L_{m} I_{r q}, \quad q_{s}=-\frac{3}{2} \frac{\omega_{s}}{L_{s}} \psi_{s}\left(\psi_{s}-L_{m} I_{r d}\right) .
$$

\subsubsection{Unbalanced grid conditions}

Under unbalanced conditions, variable $F$ in $(\alpha-\beta)$ reference frame can be described as follows:

$$
\begin{aligned}
F_{\alpha \beta}(t)= & F_{\alpha \beta+}(t)+F_{\alpha \beta-}(t)=\left|F_{\alpha \beta+}\right| e^{j\left(\omega_{s} t+\phi_{+}\right)} \\
& +\left|F_{\alpha \beta-}\right| e^{-j\left(\omega_{s} t+\phi_{-}\right)}
\end{aligned}
$$

where $\phi_{+}$and $\phi_{-}$are phase shifts in positive and negative sequences [1].

As shown in Figure 2, the conversions between the reference frame positive sequence $\left(d q^{+}\right)$and negative $\left(d q^{-}\right)$are given as follows:

$$
F_{d q}^{+}=F_{d q}^{-} e^{-2 j \omega_{s} t}, \quad F_{d q}^{-}=F_{d q}^{+} e^{2 j \omega_{s} t} .
$$

According to Eq. (11), variable $F$ is the sum of the positive and negative sequences. Therefore, in the reference frame $\left(d q^{+}\right)$, variable $F$ in Eq. (12) can be written as follows:

$$
F_{d q}^{+}=F_{d q+}^{+}+F_{d q-}^{+}=F_{d q+}^{+}+F_{q d-}^{-} e^{-2 j \omega_{s} t} .
$$

According to Eq. (13), the positive component is a constant value and the negative component oscillates with frequency $\left(2 \omega_{s}\right)[5-7]$. Eq. (13) can be expressed as a constant value and an oscillatory value: 


$$
\begin{aligned}
& F_{d}^{+}=F_{d+}^{+}+F_{d-}^{-} \cos 2 \omega_{s} t+F_{q-}^{-} \sin 2 \omega_{s} t, \\
& F_{q}^{+}=F_{q+}^{+}+F_{q-}^{-} \cos 2 \omega_{s} t-F_{d-}^{-} \sin 2 \omega_{s} t .
\end{aligned}
$$

The stator's output active power and reactive power in the positive sequence reference frame are:

$$
\begin{gathered}
p_{s}+j q_{s}=-\frac{3}{2} V_{s d q}^{+} \times I_{s d q}^{\wedge+}=-\frac{3}{2}\left(V_{s q}^{+}-j V_{s d}^{+}\right) \\
\left(I_{s q}^{+}+j I_{s d}^{+}\right),
\end{gathered}
$$

where:

$$
\begin{aligned}
V_{s d}^{+}= & -\omega_{s} \Psi_{s q}^{+}+\frac{d}{d t} \Psi_{s d}^{+}=-\omega_{s}\left(\Psi_{s q+}^{+}+\Psi_{s q-}^{-} \cos 2 \omega_{s}\right. \\
& \left.t-\Psi_{s d-}^{-} \sin 2 \omega_{s} t\right)+\frac{d}{d t}\left(\Psi_{s d+}^{+}+\Psi_{s d-}^{-} \cos 2 \omega_{s} t\right. \\
& \left.+\Psi_{s q-}^{-} \sin 2 \omega_{s} t\right)=-\omega_{s} \Psi_{s q+}^{+}+\omega_{s} \Psi_{s q-}^{-} \cos 2 \omega_{s} t \\
& -\omega_{s} \Psi_{s d-}^{-} \sin 2 \omega_{s} t \\
I_{s d}^{+}= & \frac{1}{L_{s}}\left[\Psi_{s d}^{+}-L_{m} I_{r d}^{+}\right]=\frac{1}{L}{ }_{s}\left[\left(\Psi_{s d+}^{+}+\Psi_{s d-}^{-} \cos 2 \omega_{s}\right.\right. \\
& \left.t+\Psi_{s q-}^{-} \sin 2 \omega_{s} t\right)-L_{m}\left(I_{r d+}^{+}+I_{r d-}^{-} \cos 2 \omega_{s} t\right. \\
& \left.\left.+\mathrm{I}_{r q-}^{-} \sin 2 \omega_{s} t\right)\right], \\
V_{s q}^{+}= & \omega_{s} \Psi_{s d}^{+}+\frac{d}{d t} \Psi_{s q}^{+}=\omega_{s}\left(\Psi_{s d+}^{+}+\Psi_{s d-}^{-} \cos 2 \omega_{s} t\right. \\
I_{s q}^{+}= & \frac{1}{L_{s}}\left[\Psi_{s q}^{+}-L_{m} I_{r q}^{+}\right]=\frac{1}{L}{ }_{s}\left[\left(\Psi_{s q+}^{+}+\Psi_{s q-}^{-} \cos 2 \omega_{s} t\right.\right. \\
& \left.-\Psi_{s d-}^{-} \sin 2 \omega_{s} t\right)-L_{m}\left(I_{r q+}^{+}+I_{r q-}^{-} \cos 2 \omega_{s} t\right. \\
& \left.\left.-I_{r d-}^{-} \sin 2 \omega_{s} t\right)\right] . \\
& \left.-\Psi_{s d-}^{-} \sin 2 \omega_{s} t\right)+\frac{d}{d t}\left(\Psi_{s q+}^{+}+\Psi_{s q-}^{-} \cos 2 \omega_{s} t\right. \\
& \left.\omega_{s} \Psi_{s q-}^{-} \sin 2 \omega_{s} t\right)=\omega_{s} \Psi_{s q+}^{+} \omega_{s} \Psi_{s d-}^{-} \cos 2 \omega_{s} t \\
&
\end{aligned}
$$

In DFIG, we assume that the stator resistance is negligible. Therefore, in reference $\left(d q^{+}\right)$:

$$
\begin{aligned}
V_{s d q}^{+}= & \frac{d}{d t} \Psi_{s d q}^{+}+j \omega_{s} \Psi_{s d q}^{+}=\frac{d}{d t}\left(\Psi_{s d q+}^{+}+\Psi_{s d q-}^{-} e^{-2 j \omega_{s} t}\right) \\
& +j \omega_{s}\left(\Psi_{s d q+}^{+}+\Psi_{s d q-}^{-} e^{-2 j \omega_{s} t}\right)=j \omega_{s} \Psi_{s d q+}^{+} \\
& -j \omega_{s} \Psi_{s d q-}^{-} e^{-2 j \omega_{s} t}=V_{s d q+}^{+}+V_{s d q-}^{-} e^{-2 j \omega_{s} t}
\end{aligned}
$$

Therefore, we have:

$$
\left\{\begin{aligned}
V_{s d q+}^{+} & =j \omega_{s} \Psi_{s d q+}^{+} \Rightarrow\left(V_{s q+}^{+}-j V_{s d+}^{+}\right) \\
& =j \omega_{s}\left(\Psi_{s q+}^{+}-j \Psi_{s d+}^{+}\right) \\
V_{s d q-}^{-} & =-j \omega_{s} \Psi_{s d q-}^{-} \Rightarrow\left(V_{s q_{-}}^{-}-j V_{s d-}^{-}\right) \\
& =-j \omega_{s}\left(\Psi_{s q_{-}}^{-}-j \Psi_{s d-}^{-}\right)
\end{aligned}\right.
$$

and:

$$
\begin{array}{ll}
\Psi_{s d+}^{+}=\frac{1}{\omega_{s}} V_{s q+}^{+}, & \Psi_{s q+}^{+}=\frac{-1}{\omega_{s}} V_{s d+}^{+} \\
\Psi_{s d-}^{-}=\frac{-1}{\omega_{s}} V_{s q-}^{-}, & \Psi_{s q-}^{-}=\frac{1}{\omega_{s}} V_{s d-}^{-}
\end{array}
$$

According to Eq. (14), although unbalanced, the stator voltage can still be regarded as constant $\left(F_{d^{+}}^{+}\right.$and $\left.F_{q^{+}}^{+}\right)$. Consequently, we have:

$$
\begin{aligned}
\frac{d}{d t}\left(\Psi_{s d+}^{+}\right) & =0, & \frac{d}{d t}\left(\Psi_{s d-}^{-}\right) & =0, \\
\frac{d}{d t}\left(\Psi_{s q+}^{+}\right) & =0, & \frac{d}{d t}\left(\Psi_{s q-}^{-}\right) & =0 .
\end{aligned}
$$

By replacing Eq. (22) into Eqs. (16-19) and considering Eq. (23), active and reactive powers can be expressed as:

$$
\begin{aligned}
& p_{s}=P_{s-a v}+P_{s-\sin 2} \sin \left(2 \omega_{s} t\right)+P_{s-\cos 2} \cos \left(2 \omega_{s} t\right), \\
& q_{s}=Q_{s-a v}+Q_{s-\sin 2} \sin \left(2 \omega_{s} t\right)+Q_{s-\cos 2} \cos \left(2 \omega_{s} t\right) .
\end{aligned}
$$

Considering that in VOC control $V_{s q^{+}}^{+}=0$, the active and reactive matrix forms can be described as [4]:

$$
\begin{gathered}
{\left[\begin{array}{c}
P_{s-a v} \\
P_{s-\sin 2} \\
P_{s-\cos 2}
\end{array}\right]=\frac{3}{2 \omega_{s} L_{s}}\left[\begin{array}{c}
0 \\
-2 V_{s d-}^{-} V_{s d+}^{+} \\
2 V_{s q-}^{-} V_{s d+}^{+}
\end{array}\right]} \\
+\frac{3 L_{m}}{2 L_{s}}\left[\begin{array}{cccc}
V_{s d+}^{+} & 0 & V_{s d-}^{-} & V_{s q-}^{-} \\
V_{s q-}^{-} & -V_{s d-}^{-} & 0 & V_{s d+}^{+} \\
V_{s d-}^{-} & V_{s q-}^{-} & V_{s d+}^{+} & 0
\end{array}\right] \\
{\left[\begin{array}{c}
I_{r d+}^{+} \\
I_{r q+}^{+} \\
I_{r d-}^{-} \\
I_{r q-}^{-}
\end{array}\right],} \\
{\left[\begin{array}{c}
Q_{s-a v} \\
Q_{s-s i n 2} \\
Q_{s-\cos 2}
\end{array}\right]=\frac{3}{2 \omega_{s} L_{s}}} \\
{\left[\begin{array}{c}
-\left(V_{s d+}^{+}\right)^{2}+\left(V_{s d-}^{-}\right)^{2}+\left(V_{s q-}^{-}\right)^{2} \\
0 \\
0
\end{array}\right]\left[\begin{array}{l}
I_{r d+}^{+} \\
I_{r q+}^{+} \\
I_{r d-}^{-} \\
I_{r q-}^{-}
\end{array}\right] .}
\end{gathered}
$$

The electromagnetic torque $\left(T_{e}\right)$ of a DFIG can be described as: 


$$
\begin{aligned}
T_{e} & =\frac{3}{2} \operatorname{PIm}\left[\psi_{s}(t) i_{s}^{*}(t)\right] \\
& =\frac{3}{2} P \operatorname{Im}\left[\psi_{s}(t)\left\{\psi_{s}^{*}(t)-L_{m} i_{r}^{*}(t)\right\}\right] \\
& =-\frac{3 P L_{m}}{2 L_{s}} \operatorname{Im}\left[\psi_{s}(t) i_{r}^{*}(t)\right]
\end{aligned}
$$

where ( $P$ is pole pair), the matrix form of electromagnetic torque is:

$$
\begin{aligned}
& {\left[\begin{array}{l}
T_{e-a v} \\
T_{e-\sin 2} \\
T_{e-\cos 2}
\end{array}\right]=\frac{3 L_{m}}{2 L_{s} \omega_{s}}} \\
& {\left[\begin{array}{cccc}
V_{s d+}^{+} & 0 & -V_{s d-}^{-} & -V_{s q-}^{-} \\
-V_{s q-}^{-} & V_{s d-}^{-} & 0 & V_{s d+}^{+} \\
-V_{s d-}^{-} & -V_{s q-}^{-} & V_{s d+}^{+} & 0
\end{array}\right]} \\
& {\left[\begin{array}{c}
I_{r d+}^{+} \\
I_{r q+}^{+} \\
I_{r d-}^{-} \\
I_{r q-}^{-}
\end{array}\right] .}
\end{aligned}
$$

\subsection{Control of RSC}

\subsubsection{Balanced conditions}

Eq. (10) indicates that the active and reactive powers are controlled by regulating $\left(I_{r q}\right)$ and $\left(I_{r d}\right)$, respectively. As a result, the active and reactive powers can be controlled independently using rotor current $\left(I_{r q}\right)$ and $\left(I_{r d}\right)$, respectively. According to Eq. (8), the required rotor control voltages in the $(d-q)$ reference frame are given by $[8,9]$ :

$$
\begin{aligned}
{\left[\begin{array}{c}
V_{r d} \\
V_{r q}
\end{array}\right]=\sigma L_{r} \frac{d}{d t}\left[\begin{array}{c}
I_{r d} \\
I_{r q}
\end{array}\right] } \\
-\sigma L_{r}\left[\begin{array}{cc}
-\frac{R_{r}}{\sigma L_{r}} & \omega_{s l i p} \\
-\omega_{s l i p} & -\frac{R_{r}}{\sigma L_{r}}
\end{array}\right]\left[\begin{array}{c}
I_{r d} \\
I_{r q}
\end{array}\right] \\
-\frac{L_{m} \omega_{s l i p}}{L_{s}}\left[\begin{array}{c}
\psi_{s q} \\
-\psi_{s q}
\end{array}\right]
\end{aligned}
$$

where:

$$
\begin{gathered}
\frac{d}{d t}\left[\begin{array}{c}
I_{r d} \\
I_{r q}
\end{array}\right]=\frac{d}{d t}\left(I_{r d q}\right)=\left(I_{r d q}(r e f)-I_{r d q}\right) \\
\left(k_{p d}+k_{i d} \int\left(I_{r d q}(r e f)-I_{r d q}\right),\right.
\end{gathered}
$$

where $k_{p d}$ and $k_{i d}$ are the proportional and integral gains of the current controllers.

\subsubsection{Unbalanced conditions}

Under unbalanced grid conditions, the negative sequence component of stator voltage leads to the oscillation of power (active-reactive) and electromagnetic torque with frequency $\left(2 \omega_{s}\right)$. Power fluctuations lead to increase in temperature in the stator winding, and torque fluctuations lead to mechanical tension on the rotor. In order to reduce the steady-state error value to zero and improve the accuracy of controlling, PI controller is used. Given that the simultaneous elimination of power and torque oscillations is not possible, the controller is set to Target 1 (eliminating fluctuation of stator active power) and Target 2 (eliminating fluctuation of electromagnetic torque).

\section{Target 1 (eliminating fluctuation of stator active} power)

In this case, the stator winding temperature is increased. According to Eq. (25), the required negative sequence rotor current leads to $\left(P_{s-\sin 2}=0, P_{s-\cos 2}=\right.$ $0)$ as given below:

$$
\begin{aligned}
P_{s-\sin 2} & =0 \Rightarrow I_{r q-}^{-}(\text {ref }) \\
& =\frac{1}{V_{s d+}^{+}}\left(V_{s d-}^{-} I_{r q+}^{+}-V_{s q-}^{-} I_{r d+}^{+}\right)+\frac{2 V_{s d-}^{-}}{\omega_{s} L_{m}}, \\
P_{s-\cos 2} & =0 \Rightarrow I_{r d-}^{-}(r e f) \\
& =\frac{-1}{V_{s d+}^{+}}\left(V_{s d-}^{-} I_{r d+}^{+}+V_{s q-}^{-} I_{r q+}^{+}\right)-\frac{2 V_{s q-}^{-}}{\omega_{s} L_{m}} .
\end{aligned}
$$

Accordingly, the power (active-reactive) and electromagnetic torque are given by:

$$
\begin{aligned}
P_{s \_a v}= & \frac{3 L_{m}}{2 L_{s}} \frac{\left(\left(V_{s d+}^{+}\right) 2-\left(V_{s d-}^{-}\right) 2-\left(V_{s q-}^{-}\right) 2\right)}{V_{s d+}^{+}} I_{r d+}^{+}, \\
Q_{s-a v}= & -\frac{3}{2 L_{s}} \frac{\left(\left(V_{s d-}^{-}\right) 2+\left(V_{s q-}^{-}\right) 2+\left(V_{s d+}^{+}\right) 2\right)}{V_{s d+}^{+}} \\
& \left\{\frac{V_{s d+}^{+}}{\omega_{s}}+L_{m} I_{r q+}^{+}\right\}, \\
T_{e-a v}= & \frac{3 P L_{m}}{2 \omega_{s} L_{s}} \frac{\left(\left(V_{s d+}^{+}\right) 2+\left(V_{s d-}^{-}\right) 2+\left(V_{s q-}^{-}\right) 2\right)}{V_{s d+}^{+}} I_{r d+}^{+} .
\end{aligned}
$$

Target 2 (eliminating fluctuation of electromagnetic torque)

In this case, mechanical tension on the rotor decreases. According to Eq. (28), the required negative sequence rotor current leads to $\left(T_{e-\sin 2}=0, T_{e-\cos 2}=0\right)$ given below:

$$
\begin{aligned}
T_{e-\sin 2} & =0 \Rightarrow I_{r q-}^{-}(\text {ref }) \\
& =\frac{1}{V_{s d+}^{+}}\left(V_{s q-}^{-} I_{r d+}^{+}-V_{s d-}^{-} I_{r q+}^{+}\right),
\end{aligned}
$$



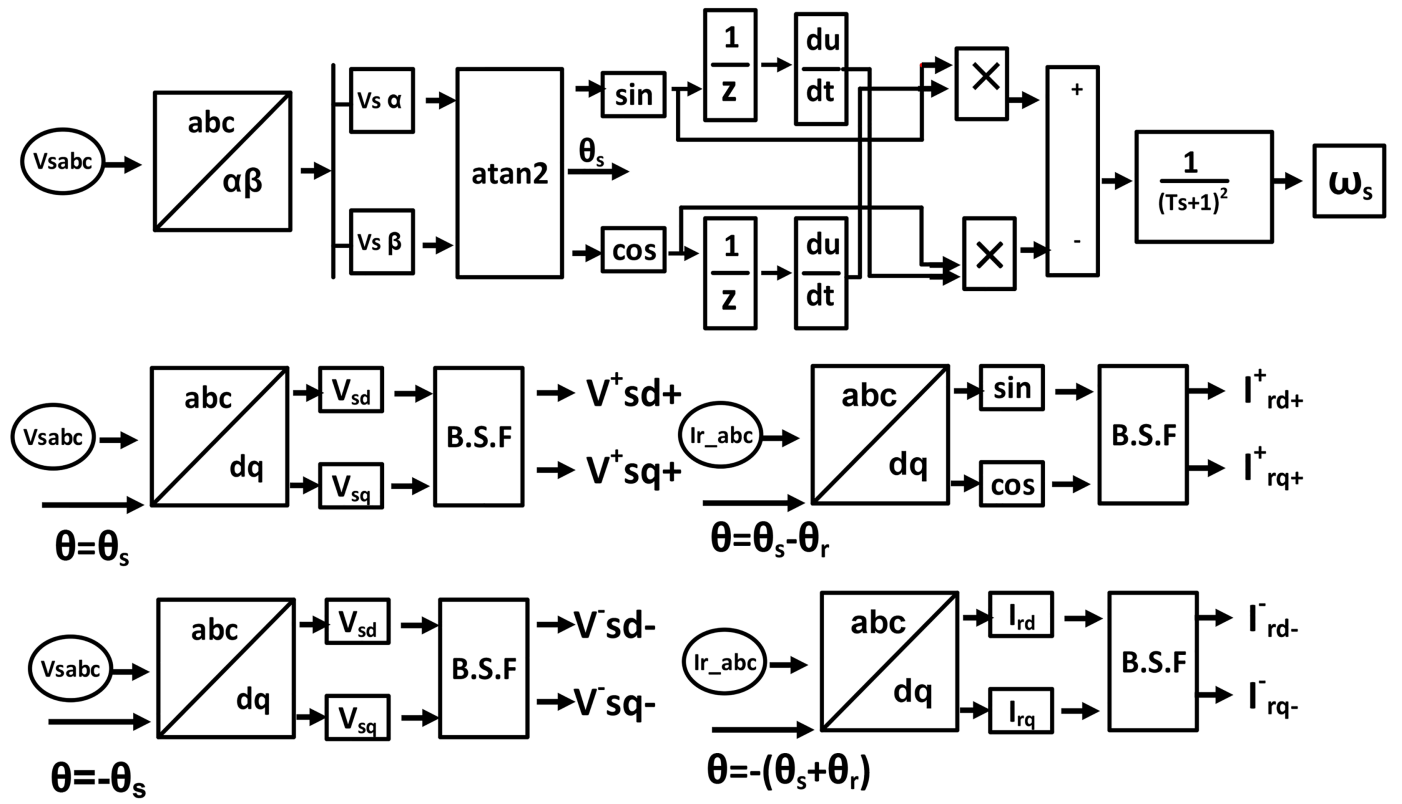

Figure 3. Block diagram of the Phase-Locked Loop (PLL).

$$
\begin{aligned}
T_{e-\cos 2} & =0 \Rightarrow I_{r d-}^{-}(\text {ref }) \\
& =\frac{1}{V_{s d+}^{+}}\left(V_{s d-}^{-} I_{r d+}^{+}+V_{s q-}^{-} I_{r q+}^{+}\right) .
\end{aligned}
$$

Therefore, power (active-reactive) and the electromagnetic torque are given by:

$$
\begin{aligned}
P_{e-a v}= & \frac{3 L_{m}}{2 L_{s}} \frac{\left(\left(V_{s d+}^{+}\right) 2+\left(V_{s d-}^{-}\right) 2+\left(V_{s q-}^{-}\right) 2\right)}{V_{s d+}^{+}} I_{r d+}^{+}, \\
Q_{s-a v}= & -\frac{3}{2 L_{s}} \frac{\left(\left(V_{s q-}^{-}\right) 2-\left(V_{s q-}^{-}\right) 2-\left(V_{s d+}^{+}\right) 2\right)}{V_{s d+}^{+}} \\
& \left\{\frac{V_{s d+}^{+}}{\omega_{s}}+L_{m} I_{r q+}^{+}\right\}, \\
T_{e-a v}= & \frac{3 P L_{m}}{2 \omega_{s} L_{s}} \frac{\left(\left(V_{s d+}^{+}\right) 2-\left(V_{s d-}^{-}\right) 2-\left(V_{s q-}^{-}\right) 2\right)}{V_{s d+}^{+}} I_{r d+}^{+} \cdot
\end{aligned}
$$

Eqs. (33)-(35) and (38)-(40) express active power and electromagnetic torque controlled by regulating $\left(I_{r d+}^{+}\right)$ and reactive power controlled by regulating $\left(I_{r q+}^{+}\right)$. In the meanwhile, controlling $\left(I_{r d-}^{-}\right)$and $\left(I_{r q-}^{-}\right)$can eliminate the oscillations of either stator active power based on Eqs. (31) and (32) or electromagnetic torque based on Eqs. (36) and (37). As a result, the average power and electromagnetic torque can be controlled independently using the rotor current positive sequence component $\left(I_{r d+}^{+}, I_{r q+}^{+}\right)$and the oscillation can be eliminated using the rotor current negative sequence component $\left(I_{r d-}^{-}, I_{r q-}^{-}\right)$. Figure 3 shows the block diagram Phase-Locked Loop (PLL). The stator's voltage frequency $\left(\omega_{s}\right)$, the phase angle of the stator voltage $\left(\theta_{s}\right)$, negative and positive sequence components of stator voltage, and the negative and positive sequence components of the rotor current can be measured by PLL. Under unbalanced grid conditions, to reduce the effects of the negative sequence component, the Band Stop Filter (B.S.F) with twice the grid frequency is used. Figure 4 shows the block diagram of a VOC for RSC control under unbalanced grid. The purpose of controlling RSC is to eliminate power fluctuations (Target 1) and torque fluctuations (Target 2). To achieve Target 1, positive and negative sequences of control components can be calculated by Eqs. (33)(35) and (31) and (32), respectively. To achieve Target 2 , components' positive and negative sequences can be calculated by Eqs. (38)-(40) and (36) and (37), respectively, where:

$$
\begin{aligned}
& V_{r d}=\frac{d}{d t} \Psi_{r d}-\left(\omega_{s l i p}\right) \Psi_{r q}+R_{r} i_{r d}, \\
& V r q=\frac{d}{d t} \Psi r q-\left(\omega_{s l i p}\right) \Psi r d+R_{r} i_{r q}, \\
& \Psi_{r d}=L_{r} i_{r d}+L_{m} i_{s d}=L_{r} i_{r d}+\frac{L_{m}}{L_{s}}\left(\Psi_{s d}-L_{m} i_{r d}\right) \\
& =\sigma L_{r} i_{r d}+\frac{L_{m}}{L_{s}} \Psi_{s d}, \\
& \Psi_{r q}=L_{r} i_{r q}+L_{m} i_{s q}=L_{r} i_{r q}+\frac{L_{m}}{L_{s}}\left(\Psi_{s q}-L_{m} i_{r d}\right) \\
& \quad=\sigma L_{r} i_{r q}+\frac{L_{m}}{L_{s}} \Psi_{s q} .
\end{aligned}
$$




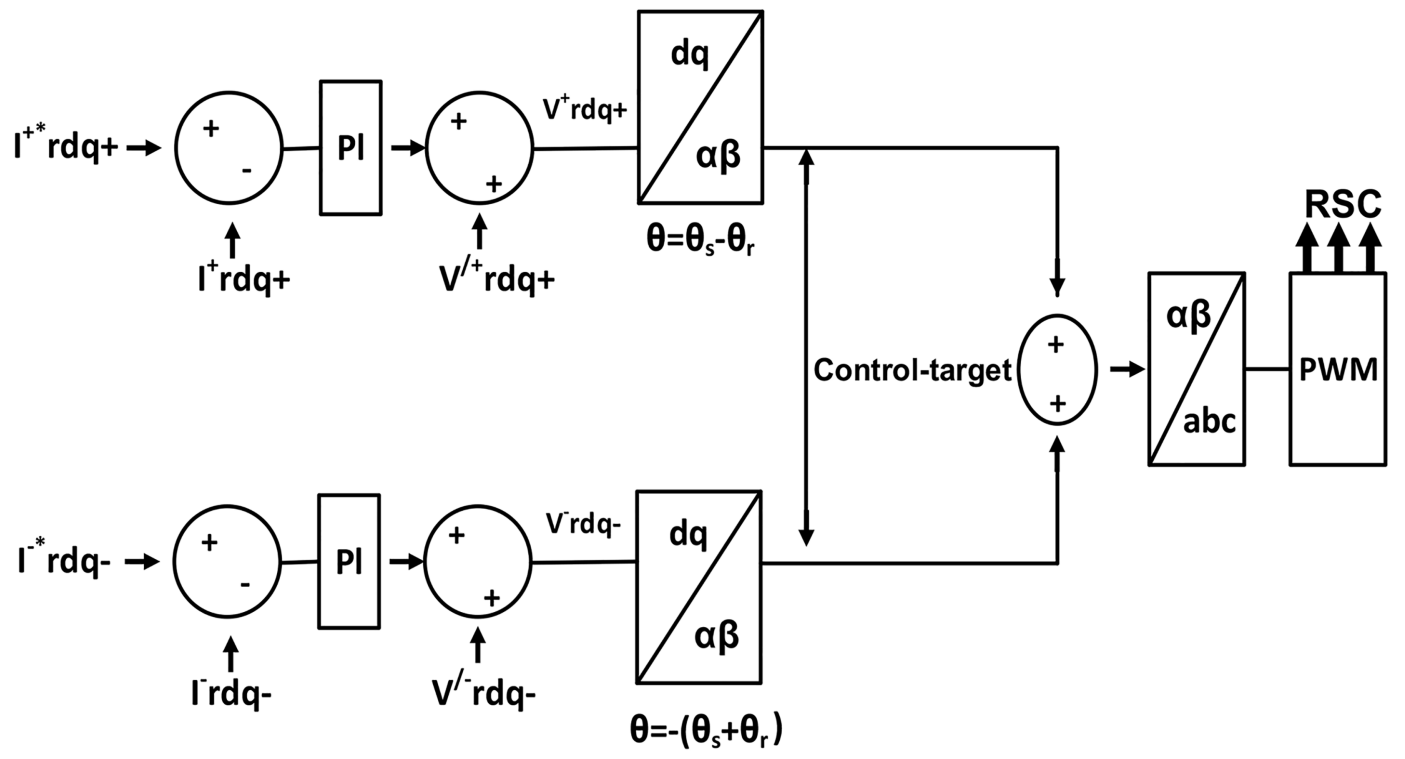

Figure 4. Block diagram of RSC control.

Upon substituting Eqs. (41) and (42) into Eqs. (43) and (44), control voltages are given by:

$$
\begin{aligned}
V_{r d+}^{+}(r e f) & =\sigma L_{r} \frac{d}{d t} i_{r q+}^{+}+V^{\prime+}{ }_{r d+}, V^{\prime+}{ }_{r d+} \\
& =-\left(\omega_{s l i p}\right) \sigma L_{r} i_{r q+}^{+}+\frac{\omega_{s l i p} L_{m}}{\omega_{s} L_{s}} V_{s d+}^{+}, \\
V_{r q+}^{+}(r e f) & =\sigma L_{r} \frac{d}{d t} i_{r d+}^{+}+V^{\prime+}{ }_{r q+}, V^{\prime+}{ }_{r q+} \\
& =\left(\omega_{s l i p}\right) \sigma L_{r} i_{r d+}^{+}-\frac{\omega_{s l i p} L_{m}}{\omega_{s} L_{s}} V_{s q+}^{+}, \\
V_{r d-}^{-}(r e f) & =\sigma L_{r} \frac{d}{d t} i_{r q-}^{-}+V^{\prime-}{ }_{r d-}, V^{\prime-}{ }_{r d-} \\
& =-\left(\omega_{s l i p}\right) \sigma L_{r} i_{r q-}^{-}-\frac{\omega_{s l i p} L_{m}}{\omega_{s} L_{s}} V_{s d-}^{-}, \\
V_{r q-}^{-}(r e f) & =\sigma L_{r} \frac{d}{d t} i_{r q-}^{-}+V^{\prime+}{ }_{r q+}, V^{\prime-} r_{r q-} \\
& =\left(\omega_{s l i p}\right) \sigma L_{r} i_{r d-}^{-}-\frac{\omega_{s l i p} L_{m}}{\omega_{s} L_{s}} V_{s q-}^{-}, \\
\frac{d}{d t}\left(I_{r d q}\right)= & \left(I_{r d q}(r e f)-I_{r d q}\right)\left(k_{p d}+\frac{k_{i d}}{s}\right),
\end{aligned}
$$

where $k_{p d}$ and $k_{i d}$ are the proportional and integral gains of the current controllers, respectively.

\subsection{Measure the rotor speed}

To measure the rotor speed of DFIG, an RPCA is used. In this algorithm, without the need for estimating the stator flux, the rotor position is measured by means of measured stator as well as rotor voltages and current. This algorithm is simple and effective and does not require direct estimation of the stator flux. One of the most important advantages of this scheme is that the calculations do not use any approximation. This algorithm is robust against variations of stator and rotor resistances and is only dependent on the estimation of the DFIG mutual inductance [16].

The stator flux in the stationary reference frame $(\alpha-\beta)$ axis can be expressed as:

$$
\Psi_{s \alpha}=L_{s} i_{s \alpha}+L_{m} i_{r \alpha}, \quad \Psi_{s \beta}=L_{s} i_{s \beta}+L_{m} i_{r \beta},
$$

The stator voltage components in the stationary reference frame can be expressed as:

$$
V_{s \alpha}=R_{s} i_{s \alpha}+\frac{d}{d t} \psi_{s \beta}, \quad V_{s \beta}=R i_{s \beta}+\frac{d}{d t} \psi_{s \alpha} .
$$

Therefore, we have:

$$
\begin{aligned}
& i_{r \beta}=\frac{\int\left(v_{s \alpha}-R_{s} i_{s \alpha}\right) d t-L_{s} i_{s \beta}}{L_{m}}, \\
& i_{r \alpha}=\frac{\int\left(v_{s \beta}-R_{s} i_{s \beta}\right) d t-L_{s} i_{s \alpha}}{L_{m}} .
\end{aligned}
$$

As is seen in Figure 5, the rotor current space vector makes the angle $\theta_{1}$ with respect to the $\alpha$-axis of the stator reference frame and angle $\theta_{2}$ with respect to the $a$-axis of the rotor reference frame. The difference between $\theta_{1}$ and $\theta_{2}$ is and can be expressed as:

$$
\begin{aligned}
& \theta_{1}=\operatorname{atan} 2\left(\frac{i_{r \beta}}{i_{r \alpha}}\right), \quad \theta_{2}=\operatorname{atan} 2\left(\frac{i_{r_{-} b}}{i_{r_{-} a}}\right), \\
& \varepsilon=\theta_{1}-\theta_{2}=\text { atan } 2\left(\frac{i_{r_{-} b} i_{r \alpha}-i_{r_{-} a} i_{r \beta}}{i_{r_{-} a} i_{r \alpha}+i_{r_{-} b} i_{r \beta}}\right),
\end{aligned}
$$




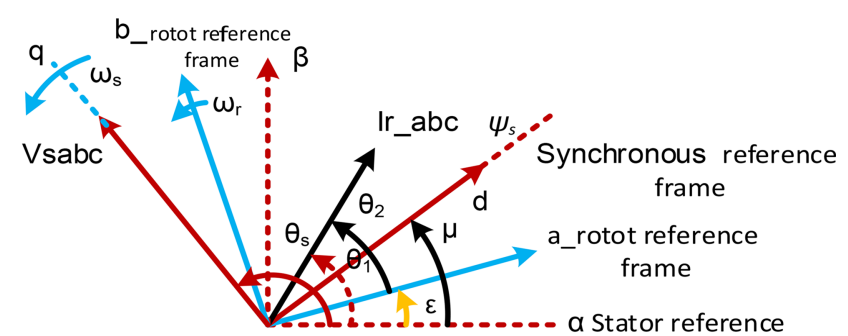

frame

Figure 5. Rotor current space vector.

where:

$$
\begin{aligned}
& i_{r_{-} a}=\frac{2}{3}\left(i_{r a}-\frac{1}{2} i_{r b}-\frac{1}{2} i_{r c}\right), \\
& i_{r_{-} b}=+\frac{1}{\sqrt{3}} i_{r b}-\frac{1}{\sqrt{3}} i_{r c} .
\end{aligned}
$$

Figure 6 shows the block diagram of RPCA algorithm which is used to measure the rotor speed of DFIG.

\subsection{Control of GSC}

To regulate DC-link voltage, an ESO based on GPI controller is employed. Figure 7 shows the block diagram of the ESO controller. In this controlling method, the voltage of the DC-link is controlled without the need to measure the current of GSC converter and because of GPI, the dynamic response is improved, voltagesettling time is reduced, and it is resistant to changes in voltage parameters. Power transfer relationship in GSC can be described as:

$$
\begin{gathered}
\frac{d}{d t}\left(0.5 C V_{D C}^{2}\right)=-\frac{V_{D C}^{2}}{R_{\text {loos }}}-P_{r}(t)+P_{g}(t) \\
\Rightarrow V_{D C}^{2}(S)=\frac{2 R_{\text {loos }} s}{C R_{\text {loos }} s+2} P_{g}(s) \\
-\frac{2 R_{\text {loos }} s}{C R_{\text {loos }} s+2} P_{r}(s)
\end{gathered}
$$

where $R_{\text {loos }}$ is the loss of switching, $V_{D C}$ voltage DClink, $C$ the capacity, $P_{r}$ output active power of the rotor, and $P_{g} \cong P_{g}($ ref $)$, where $P_{g}($ ref $)$ and $P_{g}$ are reference and output powers of GSC, respectively.

\subsection{Designing of an ESO}

Figure 8 shows the block diagram of voltage control of the DC-link voltage by GSC. This diagram consists of an internal loop for controlling converter current and an external loop for controlling and regulating the DC-link voltage $[25,26]$. In order to prevent dynamic interference between internal and external loops, the bandwidth of the internal loop is considered to be much larger than that of the external loop. Eq. (55) can be rewritten as follows:

$$
\begin{aligned}
\frac{d}{d t}\left(V_{D C}^{2}\right) & =\frac{2}{C} P_{g}(t)-\frac{2}{C}\left(\frac{V_{D C}^{2}}{R_{\text {loos }}}+P_{r}(t)\right)=\frac{2}{C} P_{g}(t) \\
& +f_{\text {total }}
\end{aligned}
$$

where $f_{\text {total }}=\frac{2}{C}\left(\frac{V_{D C}^{2}}{R_{\text {loos }}}+P_{r}(t)\right)$ is the total disturbance that consists of the external disturbance $-\frac{2}{C}\left(P_{r}(t)\right)$
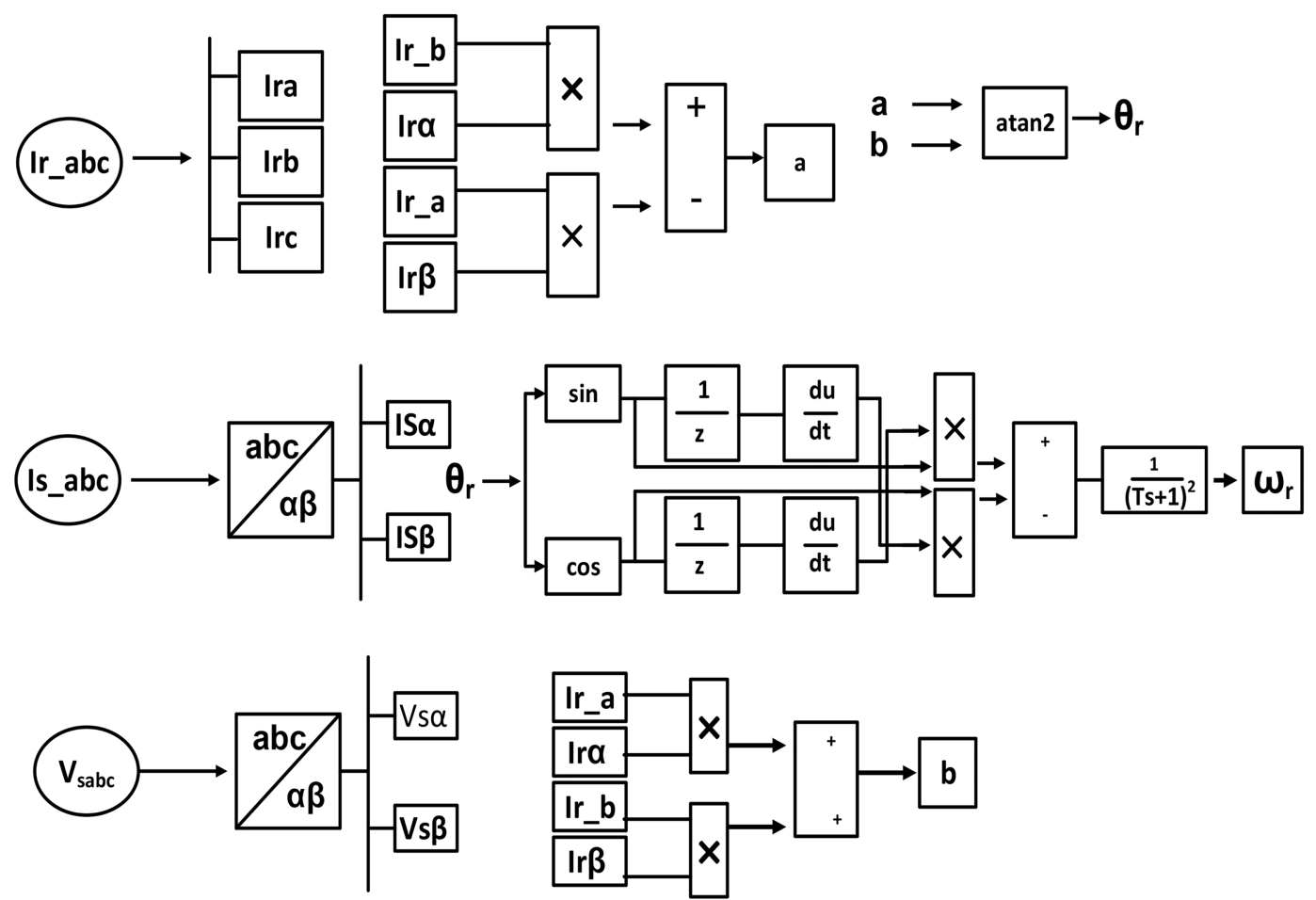

Figure 6. Block diagram of RPCA (Rotor Position Computation Algorithm). 


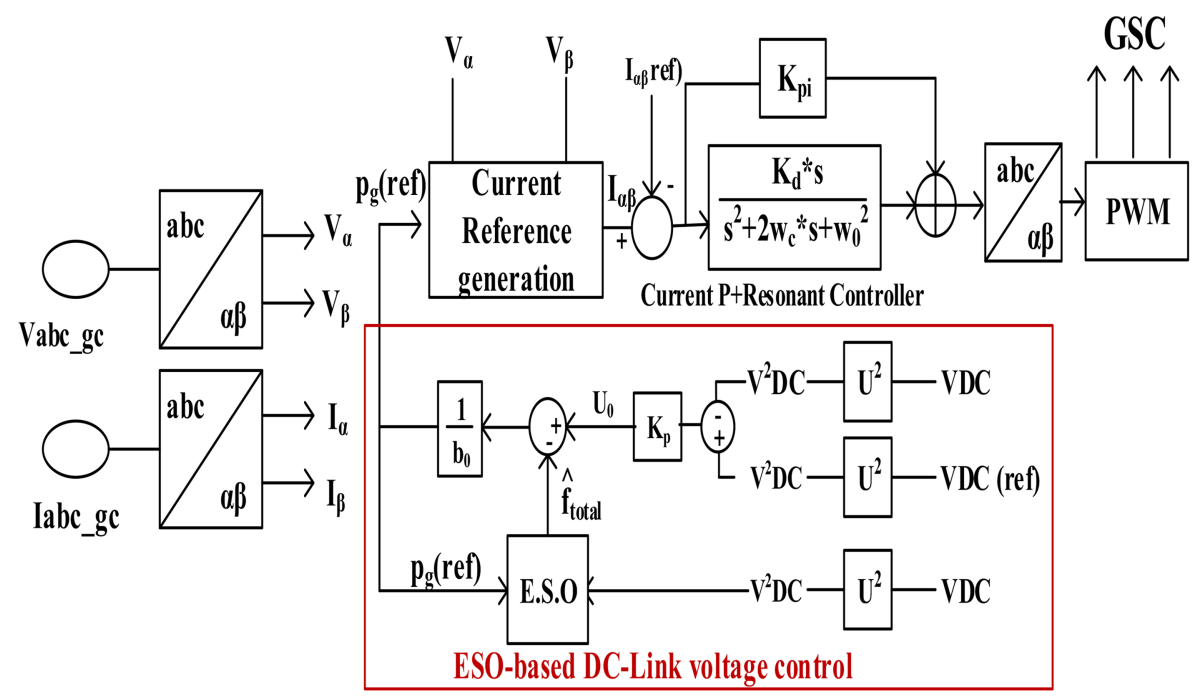

Figure 7. Block diagram of the ESO (Expanded State Observer).

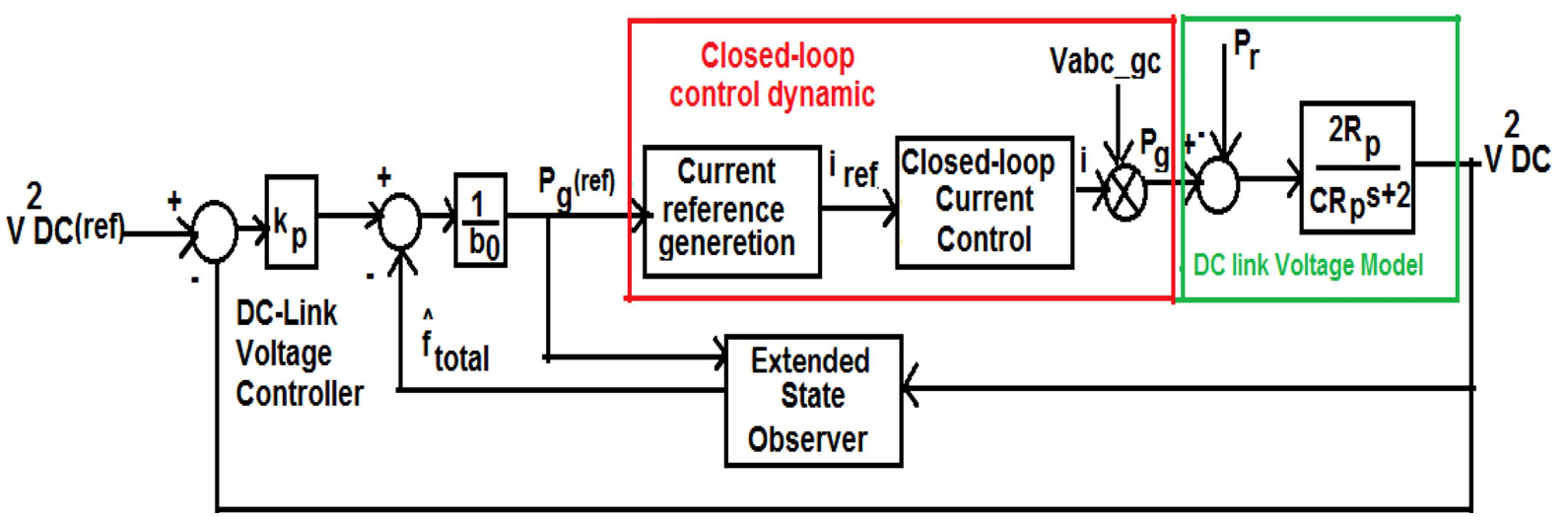

Figure 8. Block diagram of control voltage DC-link.

and internally dynamic variation $-\frac{2}{C}\left(\frac{V_{D C}^{2}}{R_{l o o s}}\right)$. In Eq. (56), $V_{D C}^{2}$ is considered as a state variable and expressed as: $x_{1}=V_{D C}^{2} ; f_{\text {total }}$ is based on Augmented Input Estimation (AIE) of state variable and expressed $[27,28]$ as:

$$
x_{2}=f_{\text {total }}=\frac{2}{C}\left(\frac{V_{D C}^{2}}{R_{\text {loos }}}+P_{r}(t)\right) ;
$$

where, $P_{g}(t)$ is the system input and indicated as: $u=P_{g}(t) ; b_{0}=\frac{2}{C}$ is the coefficient of input. Moreover, the derivative time of $x_{2}$ is denoted by $h$ and the expression is shown as: $\frac{d x_{2}}{d t}=h$. Therefore, from the aforementioned analysis, the state-space model is derived as follows:

$$
\left[\begin{array}{l}
\dot{x}_{1} \\
\dot{x}_{2}
\end{array}\right]=\left[\begin{array}{ll}
0 & 1 \\
0 & 0
\end{array}\right]\left[\begin{array}{l}
x_{1} \\
x_{2}
\end{array}\right]+\left[\begin{array}{c}
b_{0} \\
0
\end{array}\right] u+\left[\begin{array}{l}
0 \\
1
\end{array}\right] h .
$$

Based on Eq. (57), the ESO is constructed as follows:

$$
\left[\begin{array}{c}
\dot{z}_{1} \\
\dot{z}_{2}
\end{array}\right]=\left[\begin{array}{ll}
0 & 1 \\
0 & 0
\end{array}\right]\left[\begin{array}{c}
z_{1} \\
z_{2}
\end{array}\right]+\left[\begin{array}{c}
b_{0} \\
0
\end{array}\right] u+\left[\begin{array}{l}
\beta_{1} \\
\beta_{2}
\end{array}\right]\left[x_{1}-z_{1}\right],
$$

where $z_{1}, z_{2}$ are the estimated values of $x_{1}, x_{2}$ and $\left[\begin{array}{l}\beta_{1} \\ \beta_{2}\end{array}\right]$ is the gain vector of ESO. The state error equations $\left(e_{1}\right.$ and $\left.e_{2}\right)$ can be subtracting Eq. (58) from Eq. (57) as follows:

$$
\begin{aligned}
& {\left[\begin{array}{l}
\dot{e_{1}} \\
\dot{e_{2}}
\end{array}\right]=\left[\begin{array}{ll}
-\beta_{1} & 1 \\
-\beta_{2} & 0
\end{array}\right]\left[\begin{array}{l}
e_{1} \\
e_{2}
\end{array}\right]+\left[\begin{array}{c}
b_{0} \\
0
\end{array}\right] u+\left[\begin{array}{l}
0 \\
1
\end{array}\right] h} \\
& \text { and }\left[\begin{array}{ll}
-\beta_{1} & 1 \\
-\beta_{2} & 0
\end{array}\right]=H_{e} .
\end{aligned}
$$

From Eq. (59), it is known that the matrix $\left(H_{e}\right)$ will be Routh-Hurwitz stable if all roots of the characteristic polynomial of $H_{e}$, i.e.,

$$
\lambda(s)=s^{2}+\beta_{1} s+\beta_{2},
$$

are on the left half-plane. Suppose that all poles of ESO are designed to stay on bandwidth $\left(-\omega_{0}\right)$, as given below [29]:

$\lambda(s)=s^{2}+\beta_{1} s+\beta_{2}=\left(s+\omega_{0}\right)^{2} \rightarrow \beta_{1}=2 \omega_{0}, \quad \beta_{2}=\omega_{0}^{2}$.

From Eq. (61), it is shown that the design of ESO 


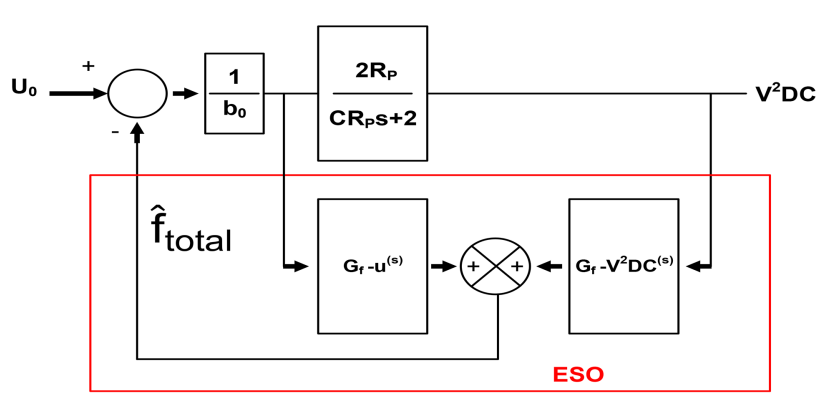

Figure 9. Block diagram equivalent transfer function of ESO.

is simplified to tune $\left(\omega_{0}\right)$ of the ESO, which greatly simplifies the design process. Choosing $\left(\omega_{0}\right)$ is an essential factor that affects the system's function. Observer's bandwidth is usually chosen 5 to 15 times the bandwidth of the controller of the DC-link voltage. Therefore, the dynamics of the estimated state enjoys fast tracking performance. Because high bandwidth reduces safety versus system noise, the bandwidth of ESO cannot be very high. In order to achieve a fast dynamic response, the bandwidth of the current loop is chosen as $300 \mathrm{rad} / \mathrm{s}$ and the voltage controller of the DC-link is chosen $20 \mathrm{rad} / \mathrm{s}$. As a result, all the three loops are separated and ESO has a high dynamic response for estimating the real state.

By substituting $\beta_{1}=2 \omega_{0}$ and $\beta_{2}=\omega_{0}^{2}$ in Eq. (58), the ESO is described as:

$$
\left[\begin{array}{c}
\dot{z}_{1} \\
\dot{z}_{2}
\end{array}\right]=\left[\begin{array}{cc}
-2 \omega_{0} & 1 \\
-\omega_{0}^{2} & 0
\end{array}\right]\left[\begin{array}{l}
z_{1} \\
z_{2}
\end{array}\right]+\left[\begin{array}{cc}
b_{0} & 2 \omega_{0} \\
0 & \omega_{0}^{2}
\end{array}\right]\left[\begin{array}{c}
u \\
x_{1}
\end{array}\right] .
$$

Eq. (62) corresponds to the Laplace domain to (Figure 9):

$$
\begin{aligned}
G_{f-u(s)} & =\frac{\hat{f}_{\text {total }}(s)}{u(s)}=\left[\begin{array}{ll}
0 & 1
\end{array}\right]\left[S I-A_{z}\right]^{-1}\left[\begin{array}{c}
b_{0} \\
0
\end{array}\right] \\
& =-\frac{b_{0} \omega_{0}^{2}}{\left(s+\omega_{0}\right)^{2}}, \\
G_{f-V_{D C}^{2}} & =\frac{\hat{f}_{\text {total }}(s)}{V_{D C}^{2}}=\left[\begin{array}{ll}
0 & 1
\end{array}\right]\left[S I-A_{z}\right]^{-1}\left[\begin{array}{c}
2 \omega_{0} \\
\omega_{0}^{2}
\end{array}\right] \\
& =\frac{s \omega_{0}^{2}}{\left(s+\omega_{0}\right)^{2}} .
\end{aligned}
$$

By combining Eqs. (63) and (64), the transfer function of $\mathrm{ESO}$ is as follows:

$$
\hat{f}_{\text {total }}(s)=\frac{b_{0} \omega_{0}^{2}}{\left(s+\omega_{0}\right)^{2}} u(s)+\frac{s \omega_{0}^{2}}{\left(s+\omega_{0}\right)^{2}} V_{D C}^{2} .
$$

\section{Results and discussion}

\subsection{Simulation results}

Simulations of the proposed control strategy for a DFIG-based generation system were carried out using MATLAB/Simulink. Figure 10 shows a schematic diagram of the implemented system. The DFIG is rated at $(2 \mathrm{MW})$ and its parameters are given in Table 1. The nominal converter DC-link voltage is set at $(1200 \mathrm{~V})$; the switching frequencies for both converters are $(2 \mathrm{kHz})$; the rotor speed is $(1.1 \mathrm{pu})$; and wind speed is $(16.2 \mathrm{~m} / \mathrm{s})$. As shown in Figure 10 , to absorb the switching harmonics generated by the two converters to the stator side, a high-frequency

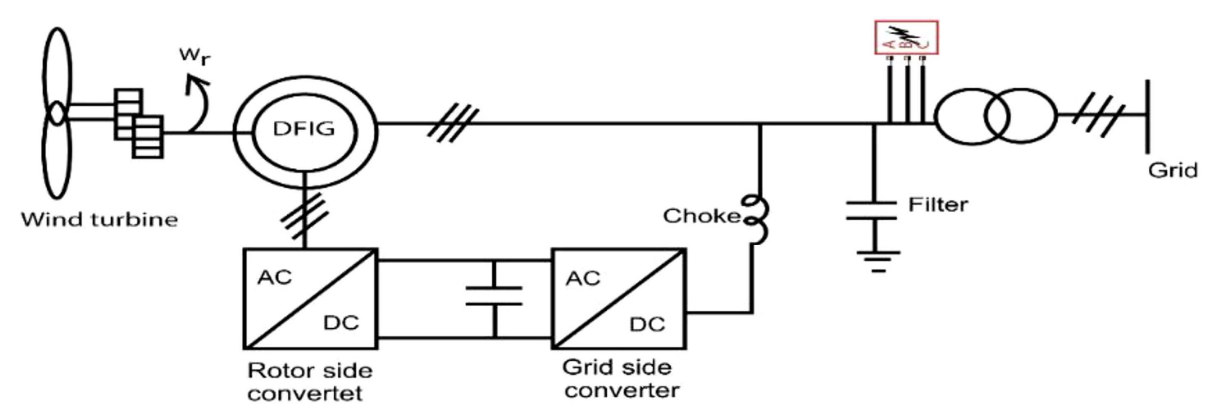

Figure 10. Schematic diagram of the simulated system.

Table 1. DFIG (doubly-Fed Induction Generator) parameters.

\begin{tabular}{lll}
\hline DFIG & Rated power & $2 \mathrm{MW}$ \\
& Voltage /frequency & $690 \mathrm{~V} / 5 \mathrm{~Hz}$ \\
& $R_{S} / R_{r}$ & $0.0108 \mathrm{pu} / 0.12 \mathrm{pu}$ \\
& $L_{m}$ & $3.362 \mathrm{pu}$ \\
& $L_{\sigma s} / L_{\sigma r}$ & $0.102 \mathrm{pu} / 0.11 \mathrm{pu}$ \\
& Inertia constant & $1.5 \mathrm{~s}$ \\
Dc-link capacitor & $C_{d c}$ & $0.0001 \mathrm{~F}$ \\
Choke & $L_{g}$ & $0.25 \mathrm{mH}$ \\
Filter & $\mathbb{R}_{f} / C_{f}$ & $0.06 \Omega / 1000 \mu \mathrm{F}$ \\
\hline
\end{tabular}



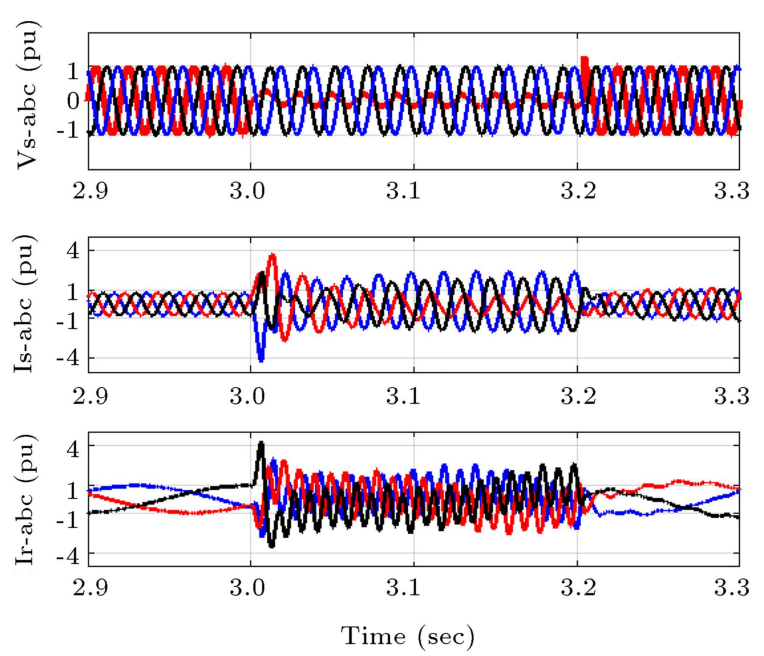

Figure 11. Voltage, current of stator, and rotor current.

AC filter is connected. The main objective of the $\mathrm{RSC}$ is to control active-reactive power and torque and in order to achieve zero state error, it is controlled using a PI PI controller. In [10], to control the performance of the RSC, the Sliding Mode Controller with Fractional order (SMC.F) based on robust control was used. In this controller, to increase the degree of freedom and robustness of the controller further, the sliding surface is selected as a fractional order form. Using a robust sliding mode controller besides increasing the performance of the controller leads to the reduction of chattering phenomenon in the input control signal. Using the decoupling of the current loops approach as a very powerful design tool for nonlinear systems makes the designed controller more robust against incoming disturbances to the system. In [11], to control the performance of RSC nonlinear robust control approach, an ESO-BS was used. This controller is designed by combining the advantages of ESO with those of the backstepping theory. This controller has the advantages of rapid response and insensitivity to disturbances. Then, ESO is constructed to overcome model error and unknown disturbances, thereby reducing the calculation burden. This controller has a simple design and small computational complexity, has a very fast transient response that effectively eliminates the overcurrent in the RSC, and eliminates electromagnetic torque in DFIG fluctuations. In this paper, to prove the results of the simulation, control of RSC with a PI controller was compared with the methods mentioned in $[10,11]$. In the simulation, unbalanced grid conditions as a short-circuit single line to ground fault within the time duration of $[3 \mathrm{~s}-3.2 \mathrm{~s}]$ were applied. Under unbalanced grid conditions for the conventional control scheme, as in Figure 11, voltage, current of stator, and rotor current become unbalanced. Figure 12 shows the positive component of stator voltage (Vspd) and the negative sequence component
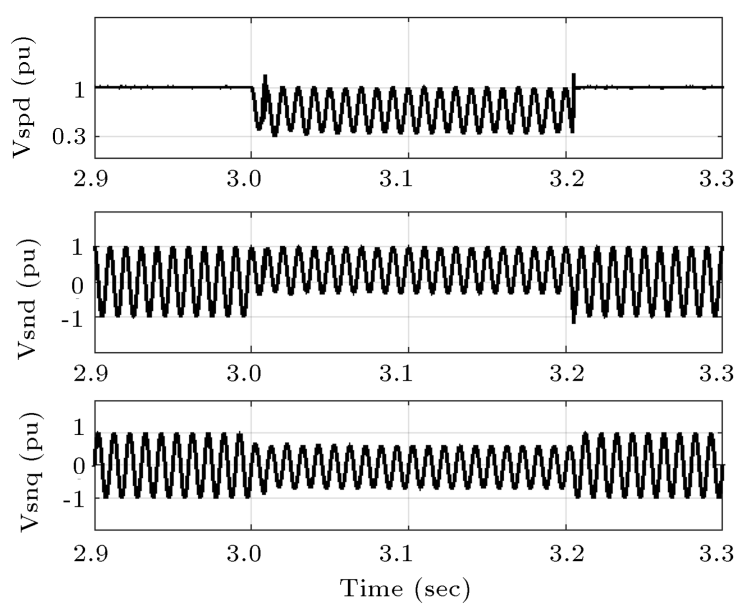

Figure 12. Stator voltage sequence conventional control with PI controller.

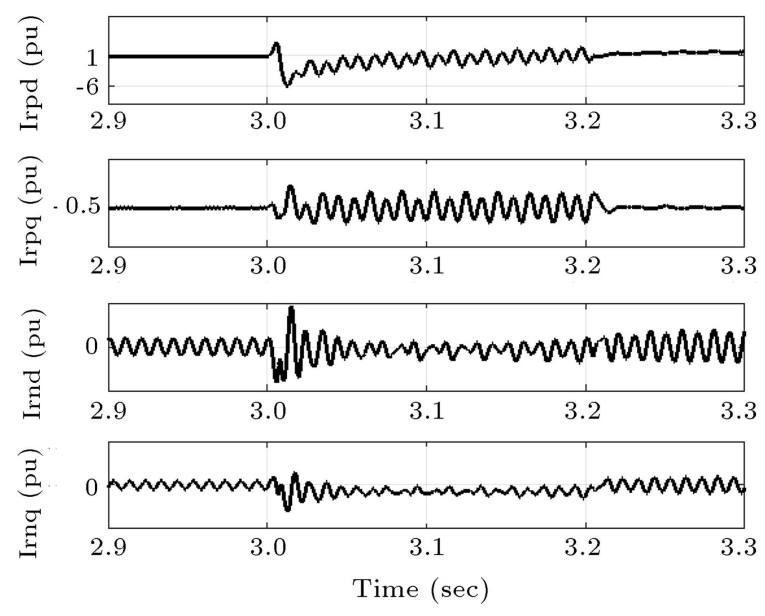

Figure 13. Rotor current sequence conventional control with PI controller.

of stator voltage (Vsnd, Vsnq) conventional control. Also, Figure 13 shows the positive component of rotor current (Irpd, Irpq) and negative sequence component of rotor current (Irnd, Irnq) conventional control. Under unbalanced grid conditions, the negative sequence component of stator voltage and rotor current causes oscillation of power (active-reactive) and electromagnetic torque with frequency $\left(2 \omega_{s}=100 \mathrm{HZ}\right)$. Figure 14 shows the power (active-reactive) and electromagnetic torque conventional control. Power fluctuations lead to increased temperature in the stator winding, and torque fluctuations cause mechanical tension on the rotor. To reduce these effects caused by the negative sequence component, the band-stop filter is employed with twice the grid frequency. Figure 15 shows the positive and negative sequence components of proposed stator voltage control, and Figure 16 shows the positive and negative sequence components of the rotor current after being passed through the B.S.F. Given that simultaneous elimination of power and torque oscillations by RSC is not possible, the 

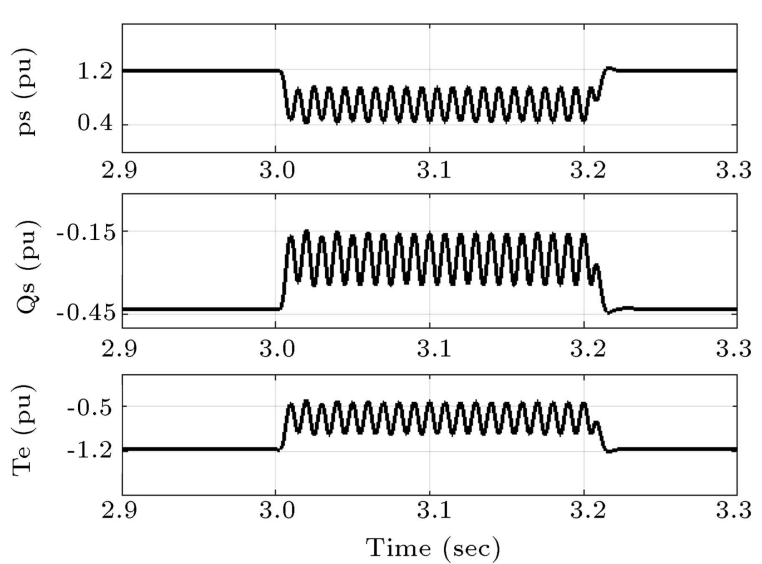

Figure 14. $\left(P_{s}-Q_{s}\right)$ and $T_{e}$ conventional control with PI controller.
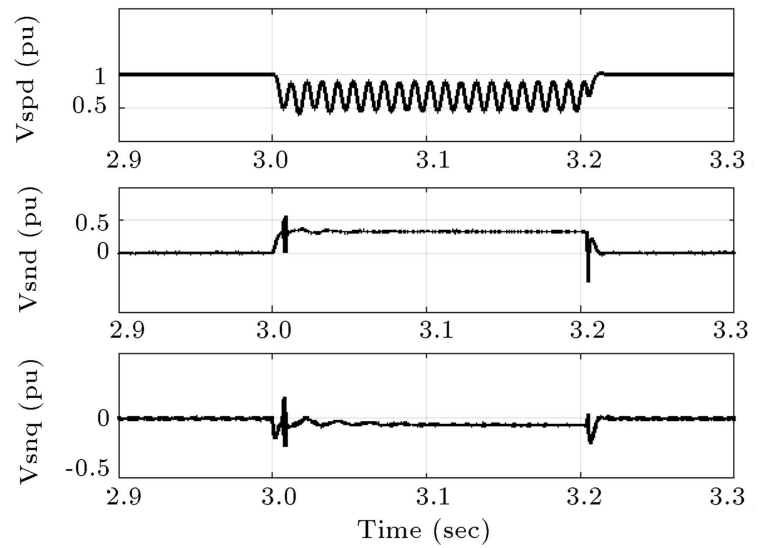

Figure 15. Proposed stator voltage sequence control with PI controller.

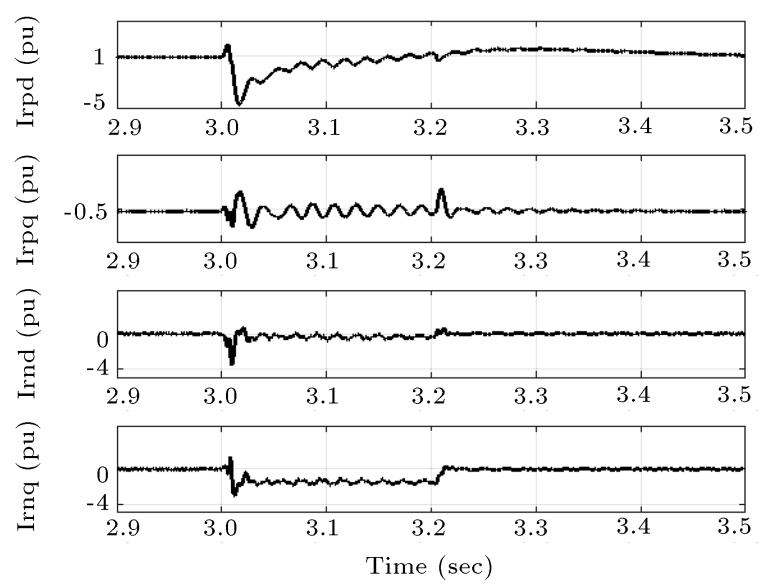

Figure 16. Proposed rotor current sequence control with PI controller.

controller of RSC is set to Target 1 (eliminating stator active power fluctuation) during [3 s-3.1 s] and switched to Target 2 (eliminating electromagnetic torque fluctuation) during $[3.1 \mathrm{~s}-3.2 \mathrm{~s}]$. According to Figure 17, the active power and torque oscillations have been reduced significantly during [3 s-3.1 s] and [3.1 s-3.2 s], respectively. Figures 18-23 show control
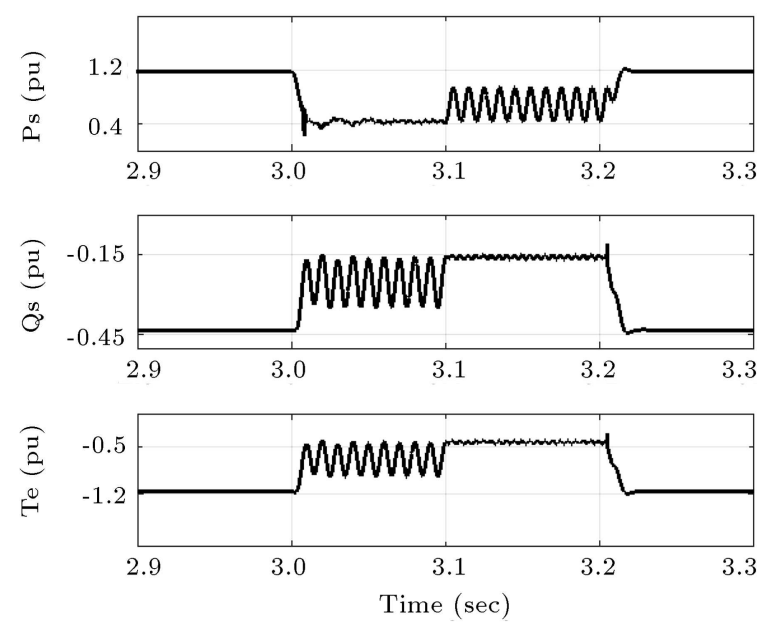

Figure 17. Proposed $\left(P_{s}-Q_{s}\right)$ and $T_{e}$ control with PI controller.
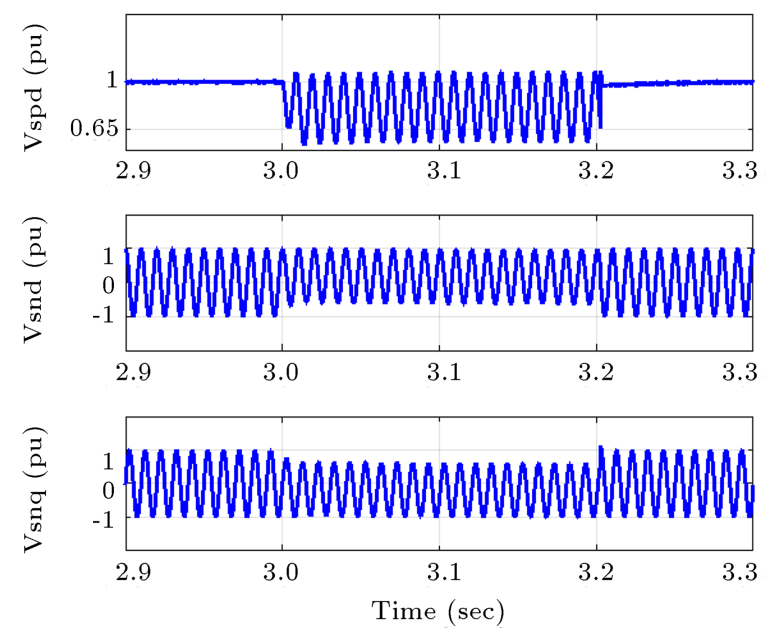

Figure 18. Stator voltage sequence conventional control with SMC-F (Sliding Mode Controller with Fractional order sliding surface) controller.

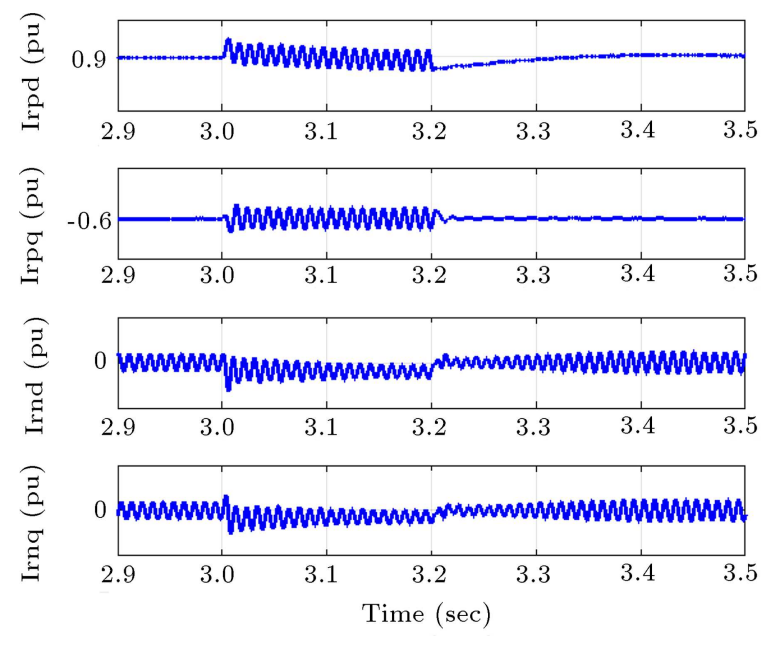

Figure 19. Rotor current sequence conventional control with SMC-F (Sliding Mode Controller with Fractional order sliding surface) controller. 

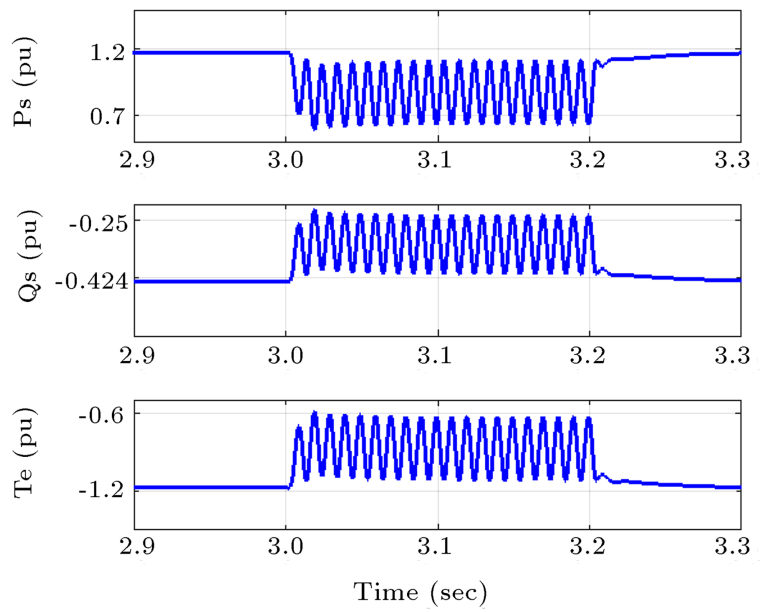

Figure 20. $\left(P_{s}-Q_{s}\right)$ and $T_{e}$ conventional control with SMC-F (Sliding Mode Controller with Fractional order sliding surface) controller.
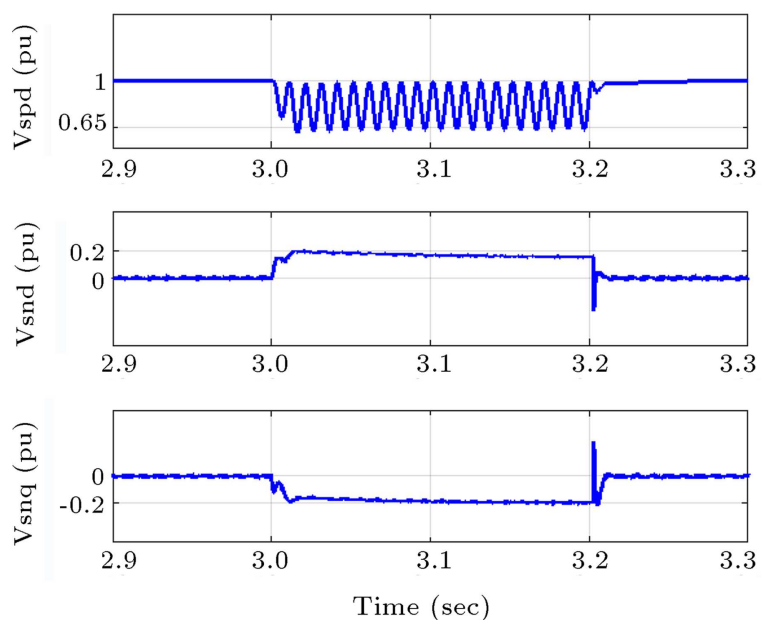

Figure 21. Proposed stator voltage sequence control with SMC-F (Sliding Mode Controller with Fractional order sliding surface) controller.

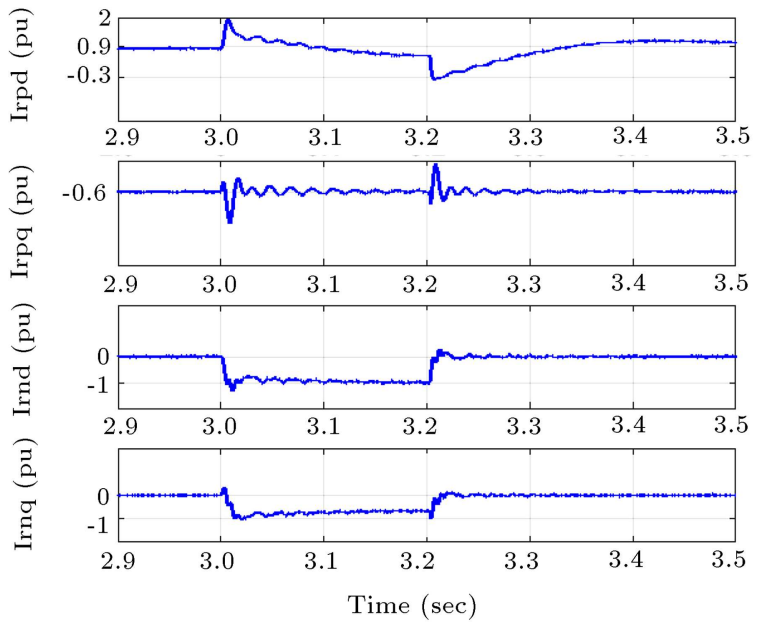

Figure 22. Proposed rotor current sequence control with SMC-F (Sliding Mode Controller with Fractional order sliding surface) controller.
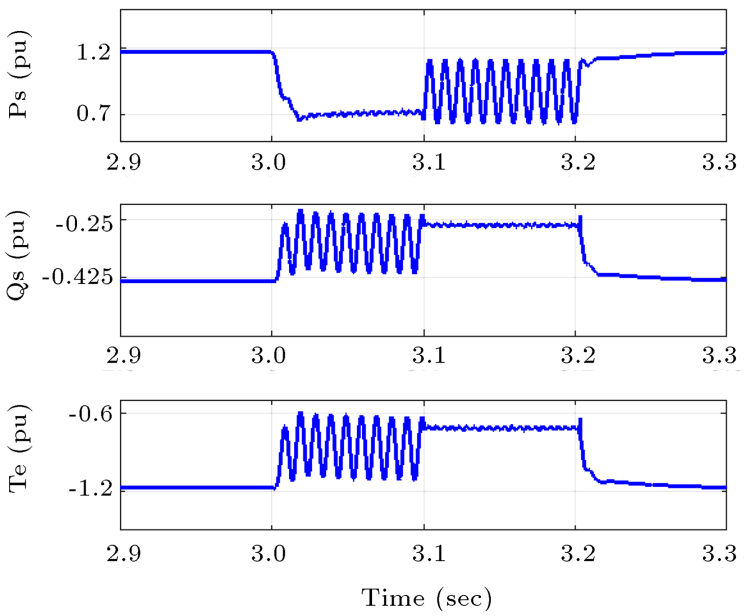

Figure 23. Proposed $\left(P_{s}-Q_{s}\right)$ and $T_{e}$ control with SMC-F (Sliding Mode Controller with Fractional order sliding surface) controller.
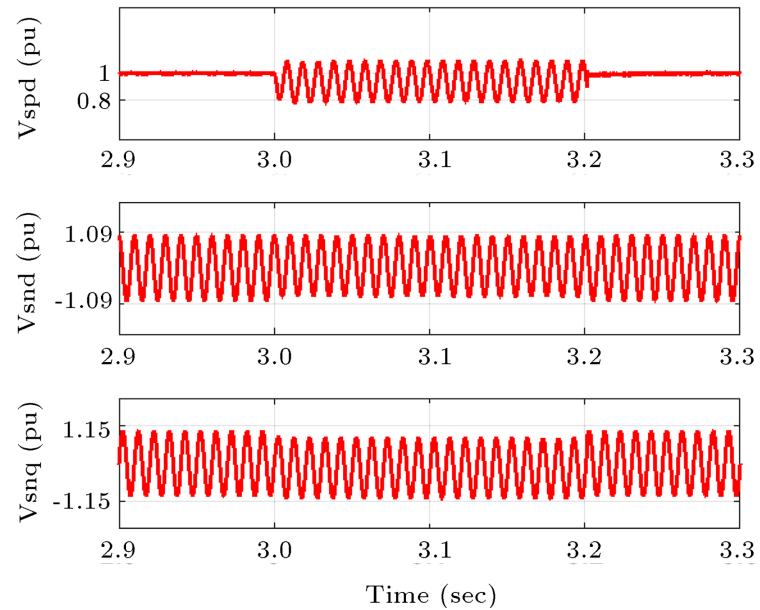

Figure 24. Stator voltage sequence conventional control with ESO-BS (Extended State Observer based on the Backstepping controller).

steps of RSC control with SMC-F, and Figures 2429 show control steps of RSC control with ESO-BS. Based on the comparison of the control results of RSC by PI, SMC.F, and ESO-BS, it was found that under unbalanced grid conditions where ESO-BS was used, the amplitude of the negative sequence component of stator voltage, rotor current, and fluctuations of power and torque were less than those obtained in the case of the SMC-F and PI controller. Thus, avoiding complex derivation of adaptive backstepping, DFIG's RSC with ESO.BS controller outperformed $\mathrm{PI}$ and SMC-F controller. The main objective of the GSC is to control the DC-link voltage and it is controlled using ESO based on a GPI controller. To prove the results of the simulation, control of GSC with ESO controller is compared with the methods PI, SMC-F, ESO-BS, and proportional (P) controllers. Figure 30 shows the DC-link voltage, and Figure 31 

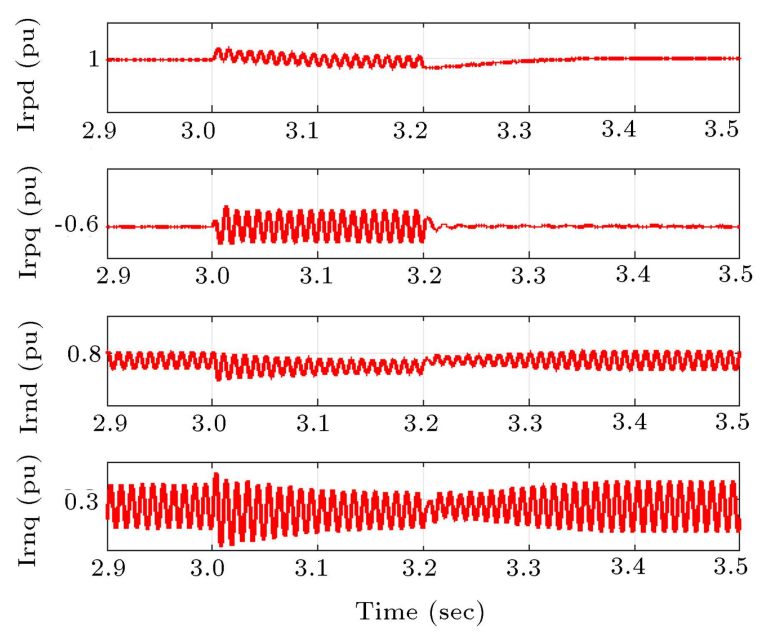

Figure 25. Rotor current sequence conventional control with ESO-BS (Extended State Observer based on the Backstepping controller).
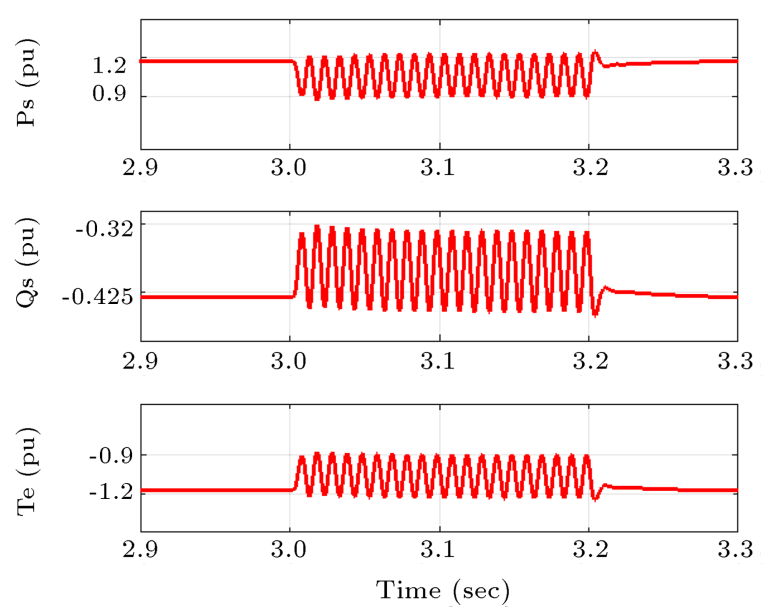

Figure 26. $\left(P_{s}-Q_{s}\right)$ and $T_{e}$ conventional control with ESO-BS (extended state observer based on the Backstepping controller).
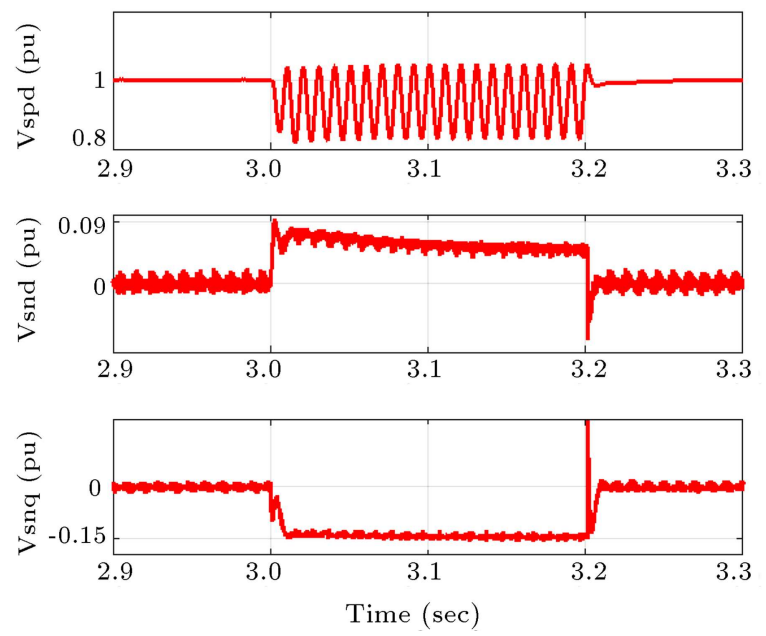

Figure 27. Proposed stator voltage sequence control with ESO-BS (Extended State Observer based on the Backstepping controller).
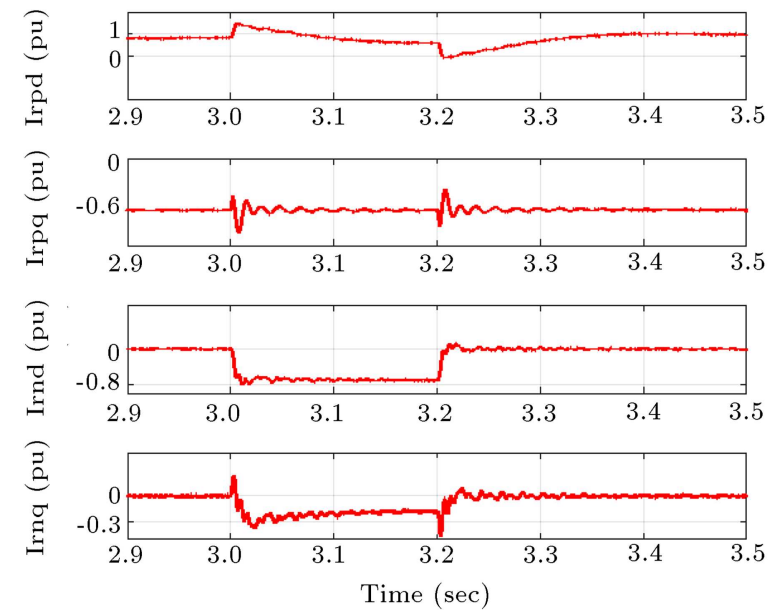

Figure 28. Proposed rotor current sequence control with ESO-BS (Extended State Observer based on the Backstepping controller).
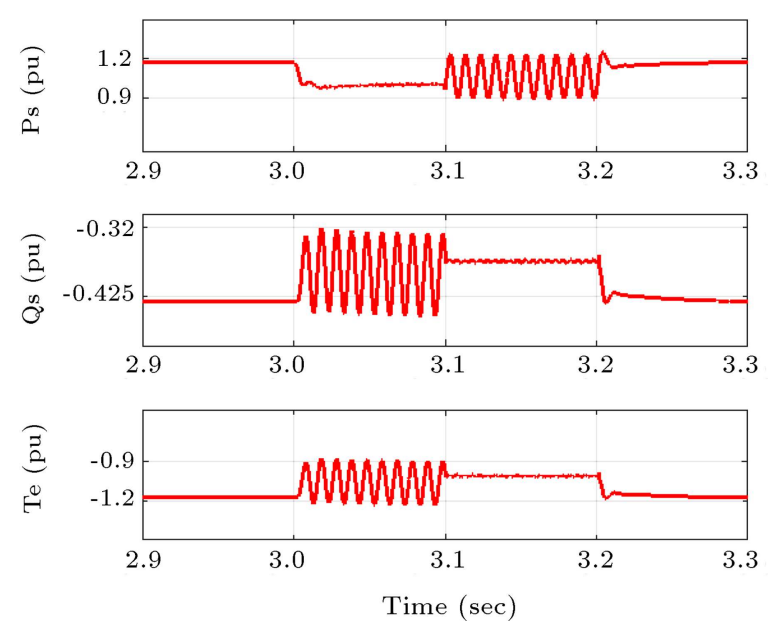

Figure 29. Proposed $\left(P_{s}-Q_{s}\right)$ and $T_{e}$ control with ESO-BS (Extended State Observer based on the Backstepping controller).

shows DC-link voltage variations during unbalanced grid conditions. Based on the ESO proposed to control for GSC control, the maximum overshoot of DC-link voltage in this controller is less than that in ESO-BS, SMC-F, PI, and P controllers. In the ESO controller, given the application of the GPI controller, settling time was reduced and voltage changes at the interval of $[3 \mathrm{~s}-3.2 \mathrm{~s}]$ were less than those in the PI, SMC.F, and $\mathrm{P}$ controllers. Therefore, the simulation results confirmed that the ESO controller for GSC control had a better performance than the other controller. In order to calculate the rotor speed, a versatile RPCA was employed. Figure 32 shows the mechanical speed of the rotor, and Figure 33 shows changes in rotor speed at the interval of $[3 \mathrm{~s}-3.2 \mathrm{~s}]$. As observed earlier, this algorithm is resistant to changes in stator voltage and remained stable under grid conditions. 


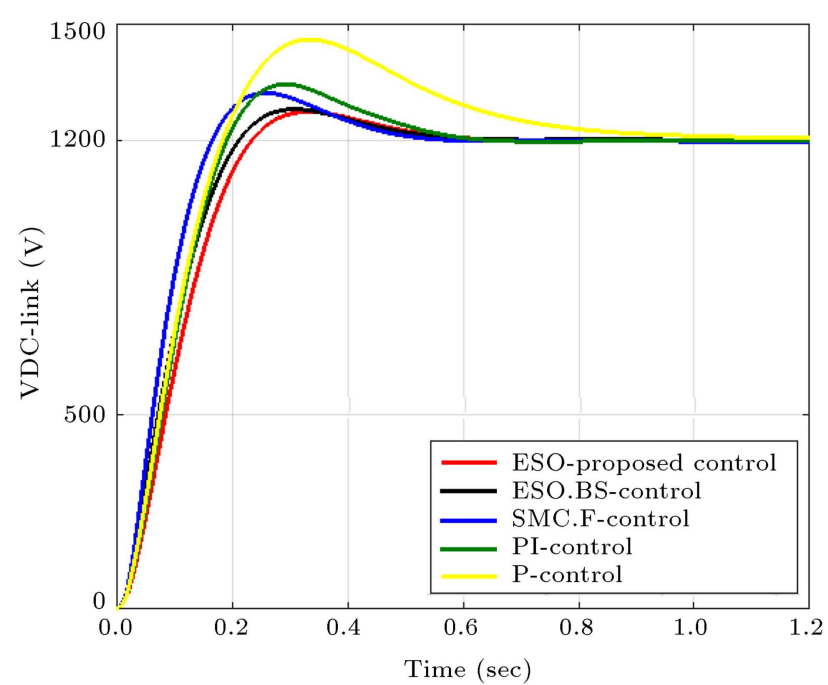

Figure 30. Voltage DC-link.

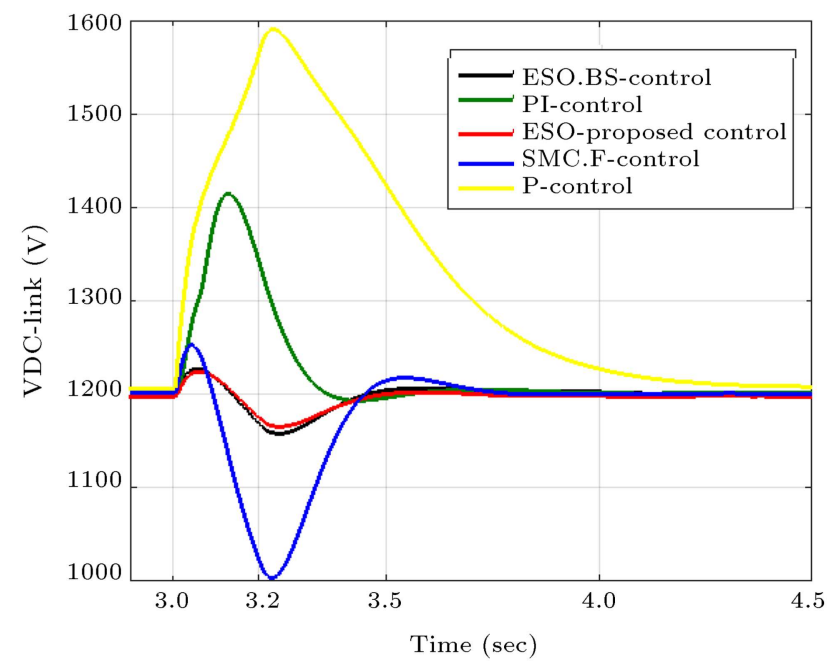

Figure 31. Variation voltage DC-link during unbalanced grid conditions.

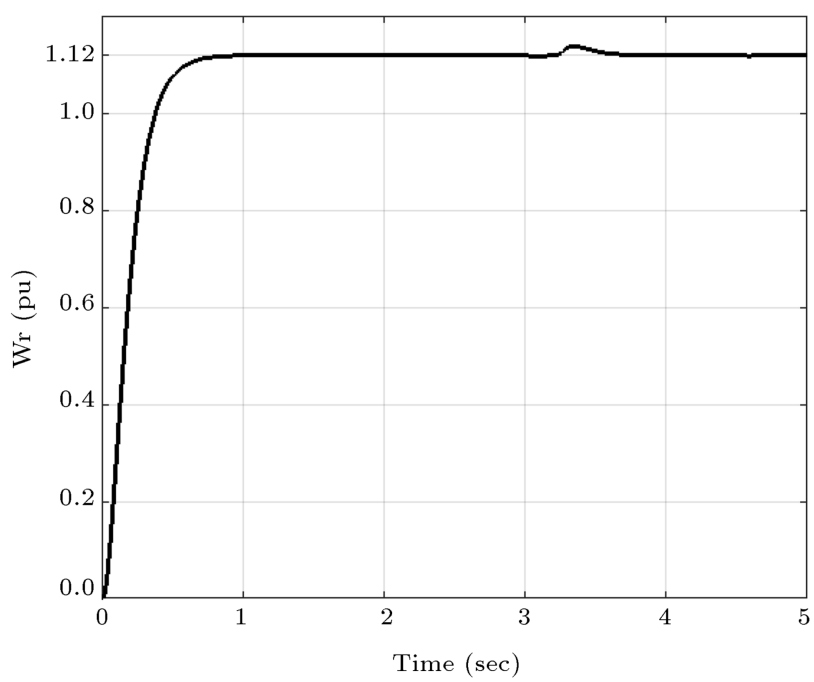

Figure 32. Rotor speed by RPCA (Rotor Position Computation Algorithm).

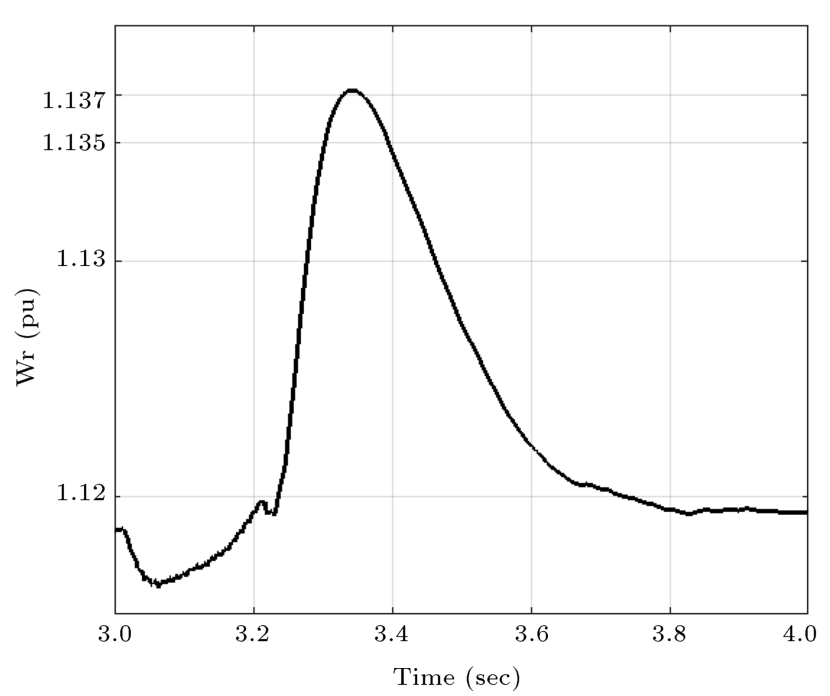

Figure 33. Variation rotor speed during unbalanced grid conditions.

\section{Conclusion}

Under unbalanced grid conditions, the negative sequence component of stator voltage led to the oscillation of power (active-reactive) and electromagnetic torque with twice the grid frequency. The controlling Rotor Side Converter (RSC) aimed to eliminate power and torque oscillations. In order to regulate DClink voltage, an Extended State Observer (ESO) was employed. In this controlling method, DC-link voltage was controlled without measuring the GSC current and due to the application of a Generalized Proportional Integral (GPI) controller, the improved dynamic response was resistant against voltage changes and settling time was reduced. To measure the rotor speed, a versatile Rotor Position Computation Algorithm (RPCA) was employed. This algorithm was resistant to changes in stator voltage and was stable under grid conditions. Simulation results confirmed that DFIG's RSC control with an ESO-BS controller exhibited a better performance than Proportional Integral (PI) controller or sliding mode controller with fractional order sliding surface (SMC-F) controller. However, the proposed ESO controller for GSC control had a better performance than ESO-BS, SMC-F, PI, and the proportional $(\mathrm{P})$ controllers, which were compared.

\section{Abbrevations}

BSF Band Stop Filter

DFIG doubly-Fed Induction Generator

ESO Expanded State Observer

ESO-BS Extended State Observer Based on the Backstepping controller

FOC Flux Orientation Control

GPI Generalized Proportional-Integral 


$\begin{array}{ll}\text { GSC } & \text { Grid Side Converter } \\ \text { PI } & \text { Proportional-Integral } \\ \text { RPCA } & \text { Rotor Position Computation Algorithm } \\ \text { RSC } & \text { Rotor Side Converter } \\ \text { SMCF } & \text { Sliding Mode Controller with } \\ & \text { Fractional order } \\ \text { SMC-F } & \text { Sliding surface } \\ \text { VOC } & \text { Voltage Orientation Control }\end{array}$

\section{References}

1. Xu, L. and Wang, Y. "Dynamic modeling and control DFIG based wind turbines under unbalance network condition", IEEE Transactions on Power System, 22, pp. 314-323 (2007).

2. Hosseini, S.M.H. and Rezvani, A.R. "Modeling and simulation to optimize direct power control of DFIG in variable-speed pumped-storage power plant using teaching-learning-based optimization technique", Soft Computing - A Fusion of Foundations Methodologies and Applications, springer, 5 May 2020.

3. Yazdani, A. and Iravan, R. "A united dynamic model and control for the voltage-sourced converter under unbalanced grid conditions", IEEE Trans on Power Delivery., 21, pp. 1620-1629 (2006).

4. Wang, Y. and Xu, L. "Control of DFIG-based wind generation systems under unbalanced network supply", Electrical Machines \& Drives Conference-IEMDC., 7, pp. 430-435 (2007).

5. Cardenas, R., Pena, R., Alepuz, S., et al. "Overview of control systems for the operation of DFIGs in wind energy applications", IEEE Trans. Ind. Electron., 60(7), pp. 2776-2798 (2013).

6. Hosseini, S.M.H. and Semsar, M.R. "A novel technology for control of variable speed pumped storage power plant", Journal of Central South University, Springer, 23, pp. 2008-2023 (2016).

7. Hosseini S.M.H. and Eslami, S. "Modeling of PSPP control system by using vector control principle and VSI", International Conference on Power Generation System and Renewable Energy Technologies (PGSRET), Istanbul, Turkey (2019).

8. Barreto, A.S.S., Salles, M.S., Lira, M.B.C., et al. "A direct power control for DFIG under a threephase symmetrical voltage sag condition", Control Engineering Practice, 65, pp. 48-58 (2017).

9. Zandzadeh, M.J. and Vahedi, A. "Modeling and improvement of direct power control of DFIG under unbalanced grid voltage condition", Electrical Power \& Energy Systems, 59, pp. 58-65 (2014).

10. Xiahou, K., Liu, Y., Wang, L., et al. "Control of DFIG's rotor-side converter With decoupling of current loops using observer-based fractional-order sliding-mode regulators", IEEE Access, 7, pp. 163412163420 (2019).
11. Cai, G., Liu, C., and Yang, D. "Rotor current control for a doubly-fed induction generator using a novel nonlinear robust control approach based on extended state observer-backstepping", SAGE Transactions of the Institute of Measurement and Control, 1, pp. 1-11 (2014).

12. Maharjan, R. and Kamalasadan, S. "A novel online adaptive sensor less identification and control of doubly fed induction generator", PES General Meeting Conference Exposition, IEEE, pp. 1-5 (2014).

13. Bhattarai., R., Gurung, N., and Kamalasadan, S. "Minimum variance adaptive speed estimation technique for vector control of doubly- fed induction generator", North American Power Symposium (NAPS), pp. 1-6 (2015).

14. Pena, R., Cardenas, R., Proboste, J., et al. "Sensor less control of doubly-fed induction generators using a rotor-current based MRAS observer", IEEE Transaction on Industrial Electronics, 55(1), pp. 330-339 (2008).

15. Carmeli, M.S., Castelli-Dezza, F., Iacchetti, M., et al. "Effects of mismatched parameters in MRAS sensorless doubly fed induction machine drives", IEEE Transaction Power Electronics, 25(11), pp. 2842-2851 (2010).

16. Datta, R. and Ranganathan, V.T. "A simple positionsensor less algorithm for rotor-side field-oriented control of wound rotor induction machine", IEEE Transactions on Industrial Electronics., 48, pp. 786-793 (2001).

17. Maharjan, R. and Kamalasadan, S. "A novel online adaptive sensor less identification and control of doubly fed induction generator", PES General Meeting Conference Exposition, IEEE, pp. 1-5 (2014).

18. Bhattarai, R., Gurung, N., and Kamalasadan, S. "Minimum variance adaptive speed estimation technique for vector control of doubly- fed induction generator", North American Power Symposium (NAPS), pp. 1-6 (2015).

19. Orlando, S., Henrique, G., Antonio, M., et al. "Nonlinear control of the doubly-fed induction generator in wind power systems", Renewable Energy., 35, pp. 1662-1670 (2010).

20. Beltran, B., Ahmed-Ali, T., and Benbouzid, M.E.H. "Sliding mode power control of variable-speed wind energy conversion systems", IEEE Transaction on Energy Conversion, 23(2), pp. 551-558 (2008).

21. Beltran, B., Ahmed-Ali, T., and Benbouzid, M.E.H. "High-order sliding mode control of variable-speed wind turbines", IEEE Trans. Ind. Electron, 56(9), pp. 3314-3321 (2009).

22. Lock, A.S., Silva, E.D., Elbuluk, M.E., et al. "A clamping current control technique, based on one cycle control OCC", IEEE Power Electronics Specialists Conference, Record, pp. 319-325 (2009).

23. Femia, N. and Fortunato, M. "Dynamic model of onecycle control for converters operating in continuous 
and discontinuous conduction modes", International Journal of Circuit Theory and Applications, 37(5) pp. 661-686 (2009).

24. Yang, J., Cui, H., Li, S., et al. "Optimized active disturbance rejection control for DC-DC buck converters with uncertainties using a reduced-order GPI observer", IEEE Transactions on Circuits and Systems, 65, pp. 832-841 (2018).

25. Lu, J., Golestan, S., Savaghebi, M., et al. "An enhanced State observer for DC-Link voltage control of three-phase AC/DC converters", IEEE Transactions on Power Electronics., 33, pp. 936-942 (2018).

26. Zhiqiang, G. "Scaling and bandwidth-parameterization based controller tuning", American Control Conference., 6, pp. 4989-4996 (2003).

27. Kumar, A. and Lu, J. "Enhanced-accuracy augmented state-space approach to steady -state modeling of resonant converters", 16 The Workshop on Control and Modeling Power Electronics, IEEE (2015).

28. Malakar, M. and Ripat, P. "State estimations of DFIG using an extended Kalman filter with an augmented state model", P Eighteenth National Power System Conference, IEEE (2015).

29. Song, Z., Xia, C., and Liu, T. "Predictive current control of three- phase grid-connected converters with constant switching frequency for wind energy systems", IEEE Transactions on Industrial Electronics, 60(6), pp. 2451-2464 (2013).

\section{Biographies}

Ali Akbar Vali received BE degree in Power Electrical Engineering from Shahid Chamran University in 1999 and MSc degree in Power Electrical Engineering from Science and Research University in 2005. He is currently PhD student in Electrical Engineering Power from South Tehran Branch.
Seyed Mohammad Hassan Hosseini was born in Tehran, Iran in 1969. He received the BSc degree in Electrical Power Engineering from Mashhad Ferdowsi University, Mashhad, Iran in 1993. He received $\mathrm{MSc}$ and $\mathrm{PhD}$ degrees in Electrical Power Engineering in 2000 and 2005 from Islamic Azad University South-Tehran Branch and Science \& Research Branch, Tehran, Iran, respectively. From 2008 to 2009, he was Deputy and from 2009 to 2011, he was the Manager of Electrical Engineering Department of Islamic Azad University South-Tehran Branch. At this time, he held the position of Associate Professor at Islamic Azad University, South-Tehran Branch. His research interests include power transformer, high-voltage engineering, pulse power generators, partial discharge, electrical insulation, substation, and hydropower.

Javad Olamaei (SM'18) received his BSc, MSc, and $\mathrm{PhD}$ degrees in Electrical Engineering in 1988, 1992, and 2008 from Tabriz University, Tabriz, Iran and Amirkabir University of Technology (AUT), Tehran, Iran and Islamic Azad University, Science and Research Branch, Tehran, Iran, respectively. He has been holding the Lecturer position from January 1997 to June 2009, the Assistant Professor position from June 2009 to February 2018, and the Associate Professor position at Islamic Azad University-South Tehran Branch since February 2018. He was the Head Manager of Islamic Azad University, South Tehran Brach from 2018 to 2019. From 2019 till yet, he is the Deputy Minister of Science, Engineering and Agriculture of Islamic Azad University. He is the author of more than 100 international journal and conference papers. His teaching and research interests include power distribution system, distribution automation system, micro grids, renewable energy, and VAR planning. 